\title{
LA NOVIA VENDIDA: ORFEBRERÍA, HERENCIA Y AGRICULTURA EN LA PROTOHISTORIA DE LA PENÍNSULA IBÉRICA
}

\author{
THE BARTERED BRIDE: JEWELRY, INHERITANCE AND AGRICULTURE \\ IN THE PROTO-HISTORY OF THE IBERIAN PENINSULA
}

\author{
por
}

\author{
MARISA RUIZ-GÁLVEZ PRIEGO
}

\begin{abstract}
RESUMEN El artículo propone dos períodos principales de intensificación agraria en la Península Ibérica: La transición del Campaniforme a la Edad del Bronce y la del Bronce Final a la Edad del Hierro. Ambos momentos se relacionan con cambios en los sistemas de herencia por vía femenina y son detectables a través del análisis de la orfebrería y de los ajuares funerarios.

ABSTRACT The paper proposes two main periods of agricultural intensification at the Iberian Peninsula: The Beaker/Bronze Age transition and the Late Bronze Age/Iron Age transition. Both moments are related to changes in women's inheritance and are detectable through the analysis of the gold and silver tresors and grave goods.
\end{abstract}

En la ópera "Prodaná nevéste", la novia vendida ', el compositor Bedrich Smetana y el libretista Karel Sabina, nos relatan una historia de amor campesina. Marenka y Jenik se aman mutuamente pero los padres de la chica quieren casar a ésta con Vasek, el hijo de un rico propietario. A la vez, Kecal el casamentero local, pretende concertar la boda de Jenik con una rica heredera.

Temas como este, han sido muy comunes en la literatura Occidental y reflejan un hecho real: cómo las bodas entre terratenientes o incluso entre pequeños campesinos, tenían menos que ver con los sentimientos que con los intereses económicos, pues el objetivo principal de los conciertos matrimoniales era acrecentar el tamaño, riqueza y poder del solar familiar.

1. La traducción española del título no es demasiado afortunada desde un punto de vista antropológico. Considero más correcta la traducción inglesa: "The bartered bride", esto es, la novia trocada 
El antropólogo británico Jack Goody, quién ha escrito ampliamente (1973, 1976 a y b, 1986 y 1990) acerca de los sistemas de matrimonio y transmisión de la herencia, señala cómo el matrimonio con dote es típico de Eurasia y del Africa Norsahariana, en tanto que el de compra de la novia es más frecuente en el Africa Subsahariana. Esto respondería a razones de tipo económico, en especial a diferencias de tecnología agraria. Así, en Africa subsahariana, la agricultura ha sido tradicionalmente itinerante, de azada, azuela o palo cavador. Ello supone que el tamaño de la parcela por individuo es muy limitado, la densidad de población baja y que por tanto, no se plantean problemas de escasez de tierra cultivable, ni tampoco grandes diferencias entre los miembros masculinos de la sociedad, en razón de la extensión de tierra que poseen y su diferente productividad. Pero más importante que ello, es el hecho que Boserup (1967 y 1984) y Goody (1973 y 1976a) señalan, de que en tales sistemas agrarios predomina la exogamia, la poliginia y la compra de la novia, porque el trabajo del campo descansa básicamente en la mujer y los hijos. Aunque tal sistema reviste muchas variantes y los objetos, perecederos o no, usados como pago de la novia, pueden pasar en todo o en parte a la familia de la mujer quien los utiliza a su vez para comprar esposas para sus hijos varones, lo importante de tal sistema es que la riqueza transferida por el novio o su familia a la de la novia actúa como compensación por la pérdida de la hija como productora pero sobre todo, por la renuncia por parte de la familia materna a ejercer derechos de filiación sobre la descendencia de la hija que pasará a formar parte unilateralmente de la familia del padre. De ahí que en tales sistemas, la mujer no transmita herencia y ésta se mantenga dentro del clan o del linaje.

Por el contrario, dentro de sistemas más complejos con empleo de arado, el sistema matrimonial que predomina es la dote. Esta se define como "El caudal que lleva la mujer cuando se casa" y que puede ser o no, un anticipo sobre su herencia que pasa de los padres a la hija. Porque lo importante de estos sistemas es que la mujer hereda y transmite sus derechos a su descendencia. La dote consiste generalmente en dinero, bienes muebles o inmuebles incluidas ocasionalmente tierras. Aunque también en este sistema existen muchas variantes, como la dote indirecta, o propiedad transferida por el novio a su familia o a la novia, con motivo de sus desposorios o de sus bodas (Goody, 1976a: 11; Lisón, 1987:83), el objeto de la dote es establecer, junto con lo aportado por el marido, un capital conyugal que ayude al matrimonio en sus comienzos, pero que, sobre todo, asegure financieramente a la mujer en caso de disolución del vínculo, bien por muerte del cónyuge o por divorcio. Aunque el marido puede tener el usufructo y administrar los bienes dotales, la propiedad es de la mujer y puede retornar a la familia de ésta en caso de que la hija muera sin descendencia.

Por ello, si los sistemas de compra de la novia son unilaterales y generalmente agnaticios, en los que predomina la dote, son cognaticios o bilaterales, pues se reconoce igual importancia a la descendencia por vía paterna o materna, ya que la propiedad o el patrimonio no están ligados necesariamente al sexo (Goody, 1976a y b).

Esta diferencia en los sistemas de filiación y herencia con respecto al propio de la agricultura de azada, radica en el hecho de que el arado permite cultivar parcelas más extensas, sostener densidades mayores de población y amentar la productividad de las tierras que se cultivan y todo ello produce presión sobre la tierra cultivable. En este tipo de cultivo, la mano de obra necesaria, mucho menor, es predominantemente masculina. Goody (1976 a: 25 y 107), señala cómo la extensión de terreno potencialmente cultivable por hombre aumenta de 6 acres $(1$ acre $=40 \mathrm{Ha})$, a 60 acres, con el uso del arado y que un hombre sólo, puede labrar 20 acres $(=800 \mathrm{Ha})$, en el mismo tiempo que una familia invierte en labrar con azada 8 acres $(=320 \mathrm{Ha}$ ) (citado en Thomas 1987). Todo ello produce diferenciación social, incluso a nivel de aldea y permite la concentración de tierras y la aparición de señores y siervos, de amos y renteros. 
En tales casos, es preciso preservar el estatus tanto de los hombres como de las mujeres de la familia. Ello explica el sistema de dote femenina, que permite la celebración de matrimonios entre iguales (homogamia), o dentro de un estrato social superior (hipergamia) (Goody, 1973:18;Tambiah, 1973:64). Ello explicaría también para Goody (1976a:51), el que en estos sistemas predomine la monogamia, pues en cada nuevo matrimonio habría que proceder a constituir un capital conyugal, en el que lo llevado por la nueva esposa en la dote, tendría que ser igualado por las propiedades aportadas por el marido.

De ahí el que las mujeres sean valoradas principalmente como reproductoras, se conviertan en instrumentos de arreglos matrimoniales, se controle celosamente su virginidad prematrimonial (Goody, 1990:210 y 273-5; Peristiany, 1968; Junquera, 1989) y que la endogamia sea una práctica frecuente entre las familias terratenientes. La razón para ello, radica en la posibilidad de que la mujer se convierta en heredera, debido a la falta de herederos varones en muchos matrimonios. Goody (1986:71), calcula un $20 \%$ aproximadamente de parejas por generación, que no tendrán hijos varones y otro $20 \%$ que no tendrán descendencia. Estas cifras podrían ser mayores de acuerdo con Goody, si se dieran altas tasas de esterilidad, homosexualidad o contracepción. Ahora bien, con la dote tanto como con la herencia, las mujeres enajenan bienes fuera de la familia o del clan; por ello, si estas transmisiones suponen bienes básicos de producción como tierra, o ganado en las sociedades ganaderas, el matrimonio entre parientes próximos se adopta como solución a la ausencia de herederos varones y a la dispersión del patrimonio. Ello puede llevar aparejado el cambio de apellidos por parte del marido o de los hijos de una heredera. Esto explica por ejemplo, el galimatías de los apellidos de la nobleza española, donde hijos nacidos de los mismos progenitores, pueden sin embargo llevar apellidos diferentes, pues en España la mujer podía ser mayorazga si no existía un varón. El cambio de apellidos permitía así, perpetuar el nombre y el linaje de una casa noble, en donde no había heredero (Lebrun/ Burguière, 1988:75).

Y creo que con ello habría que asociar la singularidad que diferencia a las mujeres españolas y portuguesas del resto de las occidentales, quienes, frente a estas, no cambian su apellido al casarse y lo transmiten a sus hijos, que usan los del patrilinaje paterno y materno (o materno y paterno en Portugal. Sobre ello, ver también Goody, 1990:364-5). Y con la posibilidad femenina de heredar y transmitir bienes inmuebles, en especial la tierra, está también ligada la cuestión del acceso de la mujer a la sucesión en el oficio, como es el caso de la institución regia (Goody, 1976b: 13).

Naturalmente esta estrategia es diferente en familias campesinas pobres, cuyas parcelas apenas dan para alimentar a una familia elemental. En tal caso se tendrá que optar bien por emplear a los hijos como mano de obra, o bien por controlar el número de su prole, lo que afecta especialmente a las niñas, menos productivas en el campo y a las que hay que dotar para poder casar. Esto explica los infanticidios femeninos en China, India o en la Europa Medieval (Goody, 1976 a: 68; Idem, 1976 b: 11; Idem, 1990:115 y 468-9).

Goody (1986:118), mantiene la tesis de que instituciones como las descritas, basadas en la transmisión de la herencia y el estatus de padres a hijos con independencia del sexo, existieron en la Europa Protohistórica, tanto mediterránea, como céltica y germánica, a partir del surgimiento en Eurasia durante la Edad del Bronce, de una agricultura técnicamente avanzada, en la que el arado o el regadío, substituyeron a una agricultura itinerante (Goody, 1990:2). Y que es la Iglesia quién, a partir del triunfo del Cristianismo en el s. IV, comienza a fomentar las donaciones y a oponerse a las estrategias hereditarias existentes, prohibiendo la adopción, el matrimonio entre primos, el concubinato, el levirato o el divorcio y las segundas nupcias, e insistiendo por el contrario, en la figura de la familia conyugal frente a la amplia, en el matrimonio por amor y mutuo consentimiento, o en la libertad del testador de 
hacerlo en contra de los intereses de los parientes. Todo ello permitió desviar el patrimonio hacia Ella en detrimento de la familia, como forma de hacer así frente a Sus crecientes necesidades en tanto que Organización dedicada a la caridad, a la educación y a la oración. El resultado de ello fue que la Iglesia se convirtió paulatinamente en el mayor terrateniente de la Cristiandad, si bien nobles y plebeyos hallaron los medios de burlar los mandatos eclesiásticos, como el propio argumento de la ópera con el que este trabajo se inicia, demuestra claramente.

Muchos arqueólogos británicos (Bradley, 1980, 1981, 1984; Barret, 1989 a y b y 1990; Barrett/ Bradley/Greenn, 1991: 120-8 y 138-9; Thomas, J., 1987; Thomas, R., 1989), se han basado en los trabajos de Goody al estudiar la Prehistoria europea y especialmente, el registro funerario y su relación con los cambios en la tecnología agraria. No obstante, y aunque la dote y otras formas de pagos matrimoniales han sido objeto de estudio en la literatura española, tanto antropológica como histórica (Casey et al., 1987; Lisón, 1987; Junquera, 1989 y en prensa; Martínez-Alier,, 1972; Redondo, 1987; Ruiz-Gálvez, E. 1990;), han alcanzado un escaso eco entre los arqueólogos españoles. Por ello, este artículo aspira a llenar tal vacío y a sugerir la existencia de cambios en tecnología agraria y en sistemas de herencia, visibles en el registro arqueológico de la Península Ibérica, muy especialmente a través de la orfebrería.

\section{ORFEBRERIA Y AGRICULTURA}

Los dos períodos principales de desarrollo de la orfebrería, son la transición Calcolítico/Edad del Bronce y el Bronce Final y transición a la Edad del Hierro. Tal hecho no es accidental, sino que está relacionado con dos momentos de intensificación agraria, de crecientes intercambios y de contactos interregionales.

La orfebrería Campaniforme/Bronce Antiguo, se concentra muy especialmente en el Centro-Norte de Portugal y en Galicia. Entre ella, vasos de oro, torques de paletas, pendientes tipo basket y gargantillas de tiras, tienen buenos paralelos en contextos de Wessex y de los Túmulos Armoricanos. Dataciones radiocarbónicas más recientes y fiables, posibilitan situar estas tumbas inglesas y bretonas, en la transición del Campaniforme a la Edad del Bronce, esto es, entre fines del III $^{\circ}$ y los inicios del II $^{\circ}$ Milenio a.C. en cronología calibrada. Dada la inexistencia de dataciones absolutas para las tumbas y depósitos españoles y portugueses, debemos suponer para ellas unas fechas semejantes a las anteriores.

Tales similitudes en orfebrería y vajilla de oro en la Europa Occidental, son la consecuencia, de acuerdo con Sherratt (1987), de un período de expansión agraria, con la llegada al área atlántica de la "Revolución de los productos secundarios", traducida desde un punto de vista social, en la tendencia a la aparición del enterramiento individual y en la creciente importancia de la figura del varón.

En fechas recientes, Criado/Fábregas (1989), señalaban cómo en algunos de los monumentos megalíticos de mediados del III Milenio a.C. en cronología calibrada (fines del mismo milenio en fechas convencionales), los ajuares documentados consisten en mazas, cinceles o hachas de combate, de morfología totalmente desconocida en la Península Ibérica y que por el contrario, reflejan contactos con Europa Occidental, donde objetos similares están bien documentados en contextos tardoneolíticos. Estos, así como la cerámica campaniforme, indicarían la creciente riqueza de los ajuares de la última fase megalítica gallega, en contraste con la paulatina pérdida de monumentalidad de las tumbas. Este fenómeno se relacionaría, de acuerdo con los mencionados autores, con la expansión de ciertos monumentos megalíticos hacia las tierras bajas más productivas pero de suelos pesados, cuya explotación habría requerido una tecnología agraria más compleja, como son el arado ligero y posiblemente tam- 
bién, el abonado animal. Dicho proceso de intensificación habría llevado a la larga a un cambio en la organización de la sociedad, con un creciente énfasis en el individuo y en le poder individual, reflejado en la paulatina monumentalidad en los enterramientos, junto con una riqueza cada vez mayor de los ajuares personales. Ello desembocaría en la aparición de los enterramientos individuales de inicios de la Edad del Bronce.

Este fenómeno, ha sido igualmente estudiado en Gran Bretaña (Bradley, 1984:63-65), donde en el Neolítico Final, la mayoría de las hachas de procedencia exótica, se concentran en las tierras de mayor potencialidad agrícola y las marcas de arado conservadas, así como los análisis polínicos, señalan un reanudamiento de la deforestación y la primera aparición de parcelaciones -land enclosures-, en una época inmediatamente anterior a la introducción del metal. La consecuencia será una renovación de los contactos con el Continente a través del Canal de la Mancha y con ello, del papel dominante del área de Wessex ya a partir de mediados del III Milenio a.C. cal, (fines del III $\%$ inicios del II ${ }^{\circ}$ convencional, Ver Bradley, 1984: Table 3,1 de pág. 40).

Desgraciadamente, la transición Campaniforme/Edad del Bronce en Bretaña, ha sido estudiada desde un punto de vista mucho más cronotipológico que socioeconómico y apenas si contamos con una información muy parcial. Por ello, podemos únicamente suponer que la aparición de las ricas tumbas armoricanas, responde a un fenómeno posiblemente similar a los anteriormente citados. Briard (1985 y 1986), señala cómo el proceso de deforestación iniciado en el Neolítico, se intensifica a fines del III $\%$ inicios del IIo Milenio a.C. en fechas calibradas. En estos momentos, tanto los diagramas polínicos como la identificación en las turberas y en los paleosuelos bajo los túmulos de niveles de incendio, parecen indicar deforestación para cultivo o pastizal. Ya en estas fechas, el polen de cereal indica prácticas agrícolas asociadas a ganadería. No hay sin embargo, indicio alguno documentado de parcelaciones de tierra o de marcas de arado y tampoco restos identificados de hábitat. No obstante en mi opinión, no podemos hacer directamente la ecuación agricultura de arado = diferenciación social + dote femenina y endogamia. Porque para que ello se produzca, es preciso un prerrequisito: poseer de modo estable y permanente unas tierras sobre las que ejercer unos derechos de propiedad transmisibles a la descendencia y sobre las que ejercitar una política de alianzas que permitan su acrecentamiento. Y ésto no es lo que me parece ver en buena parte de la Península, como tampoco en gran parte de Europa Occidental en estos momentos.

Richard Bradley (1984:158 y ss), señala cómo el paisaje del sur de Inglaterra durante el Neolítico Final y la Primera parte de la Edad del Bronce parece dominado por los monumentos funerarios y las referencias a los antepasados. Por el contrario, las evidencias de lugares de habitación son mucho más sumarias y escasas. Mientras se construyen centros ceremoniales gigantescos, los lugares de habitación son, en sus palabras (Ibidem, pág 159) "de los menos impresionantes". Por el contrario, desde el Bronce Final y sobre todo en la Edad del Hierro, esa tendencia se invierte y mientras los hábitats son claramente visibles y albergan impresionantes estructuras y zonas de almacenamiento, los lugares cultuales producen "escasa impresión" (ver también Bradley, 1991a).

Lo mismo podríamos decir de Bretaña, donde la documentación arqueológica entre el Neolítico y el Bronce Antiguo, es básica o casi únicamente funeraria. El hecho empeora a partir del Bronce Medio en cronología atlántica, cuando únicamente conocemos depósitos metálicos (Briard, 1965, 1979 y 1984). Sitios como Fort-Harrouard en el Norte de Francia (Mohen/Bailloud, 1987), con una larga aunque desigual ocupación del Neolítico a fines de la Edad del Bronce, son excepcionales.

Y si volvemos la vista hacia el Noroeste de la Península Ibérica, el panorama es similar. El paisaje aparece dominado por el mundo de los muertos, mientras que poco sabemos del de los vivos. Es interesante señalar sin embargo, que los enterramientos individuales de inicios de la Edad del Bronce, 
en su mayoría cistas, de los que conocemos un escaso número porque al contrario que los monumentos megalíticos, su documentación no procede de prospección sistemática sino de hallazgos casuales, han sido descubiertos generalmente durante la labranza, lo que significa que se sitúan en relación con las tierras de cultivo. Por el contrario, los datos habitacionales son, desde el Neolítico a bien entrada la Edad del Hierro, bastante poco impresionantes como diría Bradley.

Datos procedentes tanto de prospección intensiva como de análisis polínicos, indican la explotación por las comunidades megalíticas gallegas, de los suelos ligeros y la práctica de una agricultura cerealística por el sistema de tala y roza (Criado/Aira/Díaz-Fierros, 1986; Criado, 1988; Criado/Fábregas, 1989 a y b). No se conocen asentamientos asociados a tales monumentos, aunque quizá a su fase más reciente podrían corresponder los sitios al aire libre de O Regueiriño, A Fontenla y el nivel antiguo de Lavapés, todos en la península de Morrazo (Criado/Fábregas, 1989). Los tres presentan características similares; asentamientos breves, al aire libre y basados en una agricultura itinerante de tala y roza (Peña, 1984 a,b y c; Rodríguez/Gutián, 1984; López, 1984).

Esta pauta parece continuarse en la transición del Campaniforme al Bronce y hasta el Bronce Final. Así el horizonte más reciente de Lavapés, con cerámicas metopadas tipo Penha, dos fragmentos de moldes de fundición con adherencias de cobre y restos de bellotas carbonizadas que proporcionaron una fecha radiocarbónica no calibrada de inicios del II ${ }^{\circ}$ Milenio a.C. (fines del III Milenio a.C. cal), presenta una economía y forma de vida itinerante, similar a la del nivel anterior. Sitios del Bronce Final, como Lamela (García Alén, 1968), Chan do Carrís (Peña en prensa), o Portecelo (Vázquez/ Cano, 1988; Cano/Vázquez, 1988), reflejan la perduración de una vida itinerante, basada aún en gran parte en la recolección, en la transición hacia el I Milenio a.C. ${ }^{2}$

Susana Jorge (1986 y 1990), ha sugerido para el Norte de Portugal una ocupación permanente de los hábitats, ya desde el III Milenio a.C. El que en los yacimientos de Sâo Lourço, Circo y Senhora da Bandeira, los territorios abarcados en media hora de marcha desde el hábitat se intercepten, indica en mi opinión, que no pudieron estar ocupados al mismo tiempo; es más factible pensar que la población se desplazara de unos asentamientos a otros, una vez agotados sus recursos. Nuevamente, la ausencia de información de asentamientos hasta el Bronce Final, permite pensar, más que en falta de prospección sistemática, en su carácter perecedero y de corta duración, factor que dificulta su localización.

Es pues posible que este proceso de intensificación agraria ligado a la introducción del arado, permitiera sostener un crecimiento de población más que un asentamiento estable (R. Fábregas comunicación personal). Porque para que este se produzca, hace falta conservar la fertilidad de los suelos bien por abonado, por rotación de cultivos o por períodos más o menos largos de barbecho (ver Boserup, 1967 y 1984. Un resumen de Lambert et al., 1983:394).

Datos históricos recientes sobre el uso del suelo en Galicia y área cantábrica, dentro de sistemas agrarios tradicionales, señalan el restringido uso de abonado animal. En la cornisa cantábrica, donde la hoy típica economía ganadera es sin embargo una introducción muy reciente, el campesino apenas si podía sostener una cabeza de ganado al año para su venta en Castilla, por lo costoso de su alimentación. Pues como los pastos comunales no eran utilizables en invierno, había que prever alimento para los animales en la parte baja de los valles, donde debido al relieve, el espacio de cultivo disponible era muy limitado y la alimentación del ganado entraba por ello en competencia con la del campesino. Hasta la introducción del maíz en el s. XVIII, las tierras no daban cosecha todos los años, por el

2. He seguido el criterio de Champion et al 1984 (88): Prehistoria de Europa, de dar las equivalencias en cronología calibrada para las fechas de Neolítico a Bronce Pleno y usar fechas no calibradas a partir de Bronce Final, en que es posible establecer cronologías cruzadas con el Mediterráneo que concuerdan mejor con las fechas radiocarbónicas sin calibrar. 
excesivo lavado de los suelos a causa de la abundante lluvia y del escaso abonado, pues el número de cabezas era reducido y se practicaba un pastoreo extensivo. Ello impedía cultivar el mismo cereal más de dos años seguidos y obligaba a dejar las tierras en barbecho. De modo que sólo los huertos familiares se cultivaban de forma intensiva. Ello se complementaba con desmontes y su cultivo por tala y roza, sistema muy extendido desde las montañas de Burgos a las de León y Asturias (García Fernández, 1974).

En el caso de Galicia, el cultivo intensivo se introdujo en el s. XVIII, como consecuencia de una presión demográfica y se basó en un abundante estercolado de los suelos para evitar los períodos de barbecho. Pero la textura arenosa y porosa de éstos, provocaba un fuerte lavado y aireación de los mismos. El oxígeno reavivaba la función bacteriana, oxidando y destruyendo la materia orgánica que había que reponer rápido y en abundancia, por lo que el cultivo intensivo sólo era posible a base de grandes cantidades de abonado. Como el obtenido de la paja animal apenas daba para el cultivo de los huertos, éste tenía que conseguirse a costa de una gran inversión de trabajo, del tojo. Debido a ello, el campo no se abonaba con la frecuencia requerida. Por ejemplo, en el término de Pontevedra se hacía cada tres años y en las comarcas del interior no llegó a entrar el cultivo intensivo y se siguió practicando el barbecho. La práctica del sistema de tala y roza fue también común en Galicia (García Fernández, 1974).

La documentación medieval de Portugal indica prácticas similares, con frecuente empleo de tala y roza que provocaba fenómenos de erosión. También fue escasa la práctica del abonado con anterioridad a los s. XV-XVI, porque el ganado era escaso y la paja tenía otros usos (Oliveira Marques, 1968).

Una posibilidad alternativa o complementaria del abonado animal, sería la rotación de cultivos con leguminosas, buenas nitrogenantes, tradicional alimento del ganado $\mathrm{y}$, mezclado con los cereales, alimento de enorme valor nutricional, sustitutivo aún hoy en día en el área mediterránea, de la dieta cárnica (Zohary/Hopf, 1973:887; Rivera Núñez/Obón de Castro, 1989: 249-253). Zohary y Hopf (1989:83 y ss), señalan la extensión con la primera oleada de plantas domésticas, de una primera generación de leguminosas que como el guisante, la lenteja, el garbanzo o los yeros, son autopolinizadoras al igual que sus antepasadas silvestres, quienes por ello y frente a las de polinización cruzada, estaban preadaptadas para la domesticación. Ello sería consecuencia de que la autopolinización produce inmediatamente una barrera entre las poblaciones silvestre y cultivada y fija automáticamente los genotipos deseados. Todas estas leguminosas están documentadas en Europa Oriental y Central y en algunos puntos del Mediterráneo Occidental, a partir de la introducción del Neolítico (Zohary/Hopf 1989, map 10), si bien muchas de ellas disminuyen en cantidad y frecuencia durante la Edad del Bronce (Zohary/Hopf, 1989). Sin embargo el haba (vicia faba L.), otra de las leguminosas de mayor valor nutritivo, se reproduce principalmente por polinización cruzada y no está documentada en Europa antes del III, Milenio a.C., especialmente en lugares del Mediterráneo Occidental, como Vila Nova de Sâo' Pedro y Zambujal en el Centro de Portugal, o en diversos yacimientos Calcolíticos y Argáricos del sureste español (Zohary/Hopf, 1973:182; Idem, 1989:205-6; Hopf, 1987; Rivera Núnez/Obón de Castro/Asensio Martínez, 1988: 317-334; Stika, 1988 Tab 1).

Por el contrario, no conozco más que ambiguas evidencias de leguminosas en el Noroeste de la Península Ibérica con anterioridad a la Edad del Hierro ${ }^{3}$. Hay una excepción, el caso del yacimiento

3. Paço (1954:512), cita vagamente la presencia de haba en Pepim (Amarante), pero no menciona el contexto del hallazgo, si lo tiene. Por su parte, Ramil et al. (1990), citan la presencia de granos de leguminosa, aunque sin especificar más, junto a brassicáceas y otras, recogidas en un sondeo de un sitio de la Edad del Bronce, formado aparentemente por algunas cabañas de materiales perecederos. De la fosa de donde se extrajeron las muestras, procede una datación radiocarbónica sobre carbones, de $4.880 \pm 80$ B.P 
portugués de Buraco de Pala en Bragança (Sánchez, 1987 y 1989). Se trata sin embargo, de un abrigo en altura conteniendo silos de almacenamiento y hogares, con una secuencia que iría del Neolítico a los inicios de la Edad del Bronce. De la serie de dataciones absolutas obtenidas destaca especialmente una de $2.170 \pm 80$ a.C. en fechas convencionales (mediados del III milenio cal.), porque procede de una muestra de habas halladas en uno de los silos. Según comunicación personal de su excavadora, Buraco da Pala sería una ocupación estacional de una comunidad campesina cuyo asentamiento principal, aún no localizado, estaría en el llano. Cabe plantearse sin embargo, si lo que Buraco de Pala representa no es posiblemente una trasterminancia ganadera, en la que los pastores, como en el caso de los Tolmos de Caracena (Soria) (Jimeno, 1984;214), cultivan "in situ" para ellos y para complemento del forraje animal. Pues no resulta rentable que el pastor suba a los pastos de verano, cargado con pesados sacos de harina y otros alimentos. Si mi hipótesis es acertada, la presencia de leguminosas no indicaría necesariamente aquí prácticas de rotación y preservación de la fertilidad de los suelos. Por otra parte, aún durante gran parte de la Edad Media y Moderna de Portugal, el uso de las leguninosas como nitrogenante estuvo poco generalizado (Oliveira Márques, 1968).

En Gran Bretaña, aunque las leguminosas están documentadas al menos desde el Neolítico reciente en el sur de Gales (Whittle, 1985:249), la introducción de algunas de ellas como los guisantes y la vicia faba, muy ricas en proteínas, no parece anterior a mediados o fines del $\mathrm{II}^{\mathrm{o}}$ Milenio a.C. (Mercer, 1981: XVIII).

Así pues, es muy posible que el escaso uso o incluso la total ausencia de nitrogenantes, el escaso abonado animal, la práctica de tala y roza y seguramente, la necesidad de períodos de barbecho relativamente largos, expliquen la imposibilidad de los campesinos de la transición Campaniforme/ Edad del Bronce, de mantenerse estables durante largos períodos, en los terrenos de cultivo de Europa Occidental.

Bradley (1984:91-4), señala como causas del ocaso de la primera etapa de la Edad del Bronce en el Sur de Inglaterra, el uso incorrecto del suelo que conduce a la aparición de fenómenos de podzolización y formación de turberas, acelerado en parte por procesos de deterioro climático, pérdida en algunas áreas del monopolio de las redes de intercambio que suplían de metal continental y emergencia de otras zonas dominantes. Todo ello, obligó a una reorganización de las prácticas agrarias. Por su parte Criado/Fábregas (1989), indican que el impacto humano sobre el paisaje provocó la conversión de zonas de pastos en páramos, clareo de zonas forestadas, el inicio de la formación de turberas...etc, procesos erosivos que se tradujeron todos ellos en degradación de la tierra cultivable, si bien, acentúan, no se trataría de una auténtica catástrofe ecológica.

En cualquier caso, todos estos datos parecen apoyar la idea de que, no obstante la posible introducción del arado ligero y de nueva tecnología agraria en contextos campaniformes, gran parte de Europa Occidental es aún incapaz de conservar la fertilidad de los suelos y por ello, de mantenerse de forma estable y permanente en las tierras que ocupan.

Es por ello que la mayoría de los autores consideran la sociedad de este momento, organizada sobre una red de alianzas entre individuos de alto rango, pero en la que el poder derivaría más del acceso al conocimiento ritual, del control de los intercambios y del trabajo del suelo que de la propiedad misma de la tierra cultivable. Rowlands (1980), Bradley (1980 y 1984:63), Kristiansen (1982) o Shennan (1982), han definido tales sociedades de la Edad del Bronce como basadas en una economía de bienes de prestigio, si bien hay que entenderlo aquí, de modo diferente al modelo formulado para las Jefaturas Centroeuropeas de la Edad del Hierro que comercian con organizaciones políticas más complejas (Frankestein/Rowlands, 1978; Barrett/Bradley/Green, 1991: 239). Se trata aquí más bien, de lo que Renfrew (1982:6; Renfrew/Cherry, 1984), define como "relaciones entre sistemas políticos similares", 
a través de cuyas redes de intercambio fluyen no sólo objetos materiales, sino también información y conocimientos ritual y esotérico (Renfrew, 1984:6; Bradley, 1984:63; Goody, 1987: 161-4; Helms, 1988). Ello explicaría el alto grado de convergencia cultural y la aparición de similitudes en las formas de servir comida y bebida en Europa entre el Calcolítico y el Campaniforme, a los que Sherratt (1987) alude, y que estarían asociados a la expansión del arado y otros elementos de la Revolución de los productos secundarios.

A propósito del consumo comunitario de bebida -alcohólica por supuesto- señalaba recientemente Dietler (1990), cómo en las sociedades sin papeles políticos institucionalizados, pero con nacientes diferencias jerárquicas como las sociedades Big Men, la introducción de nuevas formas de bebida puede ser manipulada para acumular símbolos duraderos de riqueza por medio de su conversión dentro de diferentes esferas de intercambio. Un ejemplo de ello son los "work-party feasts", en los que el anfitrión invierte una parte de su capital en la producción de bebidas alcohólicas, con las que agasajar a los vecinos, parientes y deudos que vienen a ayudarle gratuitamente en la cosecha de sus campos. Es la capacidad de acumular mano de obra, más que la de acumular tierra, lo que es vital aquí.

Bajo tal perspectiva, sería más explicable un tesoro como el de Caldas de Reyes (Ruiz-Gálvez, 1978) (fig, 1ํ), el más impresionante atesoramiento de oro del Bronce Antiguo, no sólo en la Península Ibérica sino hasta donde sé, de toda Europa Occidental. La parte conservada del mismo pesa más de 30 kgs, aproximándose su peso original a los $50 \mathrm{kgs}$. Aparte los vasos y el peine que indican la introducción de nuevas formas de bebida y adorno personales (Sherratt, 1987), destacan del conjunto por su espectacularidad, el gran torques de paletas con cerca de $1 \mathrm{~kg}$ de peso y 22,6 $\mathrm{cms}$ de diámetro, que tal vez haya que ver (Peña Santos comunicación personal), como un portalingotes del que colgaban los brazaletes y no como un objeto de adorno; y los 21 brazaletes o lingotes macizos, con un peso medio de 483 grs, superando algunos los 700 grs. El tamaño y peso excepcionales del torques y de los brazaletes inclina a considerarlos como lingotes y por tanto, como atesoramiento de materia prima costosa y preciada.

Depósitos de tales dimensiones no se conocen en estos momentos en Europa Occidental, pero sí en cobre o bronce en centroeuropa donde Harding (1984), señala la coincidencia entre grandes atesoramientos de objetos metálicos y la cercanía a vetas de mineral. Sherratt por su parte (1976), los relaciona con la primera acumulación de riqueza personal y la posible aparición de Big Men.

Análisis realizados sobre piezas inglesas pertenecientes a contextos de Wessex I, indican no sólo la existencia de estrechos contactos con Bretaña sino, asimismo, que el metal empleado en la fabricación de los puñales de Wessex I es importado (Bradley, 1984:87-8; Ottaway, 1974). Visto que Bretaña no es productora de cobre y la Península por el contrario lo es, resulta altamente probable que el metal empleado en los puñales armórico-británicos procediera, entre otras, de esta fuente. Aunque muestras vetas de cobre más ricas se sitúan en el SE y SO, ningún indicio permite pensar que éstas fueran las que abastecieran al mercado atlántico. Por ello y de acuerdo con la concentración de hallazgos atlánticos del Bronce Antiguo, hay que concluir que fue el cobre y el oro del Noroeste el que cubrió la demanda externa, cuyo volumen de otro lado, no debió ser muy grande dado su carácter más emblemático que práctico (Renfrew, 1986; Ruiz-Gálvez, 1987). Ello permitiría al Noroeste formar parte del circuito de contactos atlánticos dentro de esas relaciones entre sistemas políticos similares.

Los cambios en la balanza de poder de unas regiones a otras, la puesta en explotación de nuevas y más cercanas vetas de mineral, procesos de degradación de los suelos...etc, explicarían igualmente la pérdida de importancia del Noroeste peninsular a fines del Bronce Antiguo ( $1^{\underline{a}}$ mitad del II $^{\circ}$ milenio a.C. en fechas convencionales, o inicios del mismo milenio, calibradas). Esta región, no volverá a entrar plenamente en los circuitos de intercambio occidentales hasta el Bronce Final. 
El modelo que he esbozado aquí, no se puede aplicar sin embargo en conjunto, a toda la Península Ibérica y mucho menos al área del Sureste, donde no obstante existir oro, cobre y plata nativa, las muestras de joyería que conocemos, son mucho más modestas. Tras los ajuares funerarios exóticos, conteniendo huevos de avestruz y marfil de contextos Calcolíticos y Campaniformes de los Millares (Harrison/Gilman, 1977), donde Chapman (1981 a y b), detecta diferencias de riqueza de unos clanes a otros, la mayoría de los enterramientos argáricos son bastante sencillos. Apenas uno o varios cacharros, algunos de ellos empleados previamente para almacenamiento o consumo de alimentos, y algunos pocos objetos metálicos entre armas, vestimenta y adorno. Tal parquedad contrasta aún más en una región que tiene acceso a vetas de mineral.

En su análisis de las necrópolis argáricas Lull/Estévez (1986), distinguen varias categorías sociales de acuerdo con la composición y valor de los ajuares. A este análisis podrían ponerse varias objeciones, como extropolar datos de tumbas sexadas a otras no sexadas (Ibidem:449), o incluir como posibles enterramientos femeninos los que llevan copa (Ibidem:450), pues en las sociedades tradicionales, la bebida "es cosa de hombres". Con todo, cabe destacar de dicho estudio varios hechos significativos. $1^{\circ}$, El que en los enterramientos de rango superior, mayoritariamente masculinos, aparezcan no obstante algunos femeninos. 2o, El que existan enterramientos infantiles, algunos de ellos con ajuar y con ajuar rico. Pero sobre todo, 3 e el que las diferencias de riqueza en los ajuares, no parezcan relacionarse con el sexo ni con la edad del individuo.

El Sureste, frente al resto de la Penísula Ibérica, testimonia una ocupación estable y permanente de los hábitats y no sólo de los territorios, desde los Millares en adelante. Poblados de estructuras sólidas y permanentes, muchas veces pétreas, vienen acompañados de sus correspondientes cementerios, situados en proximidad o incluso en el interior de sus recintos. En pocas palabras, reflejan permanencia y continuidad

El arado (Peters/Von der Driesch, 1990:75), las leguminosas, el abonado animal y quizá también el policultivo mediterráneo, habrían posibilitado ésto y provocado paulatinamente cambios en el significado del suelo, así como en los sistemas de propiedad y de transmisión de la herencia. Y cabe recordar en tal sentido, cómo algunos especialistas (Ayala/Rivera, 1987 citado en Rivera et al., 1988:323), consideran que el Sureste español es uno de los focos de domesticación del haba. Por ello, lo que indicarían los ajuares de las tumbas argáricas, son categorías sociales heredadas y no adquiridas y la aparición de sistemas de filiación bilateral, propios de economía compleja de arado. Así habría que interpretar la inclusión de algunos enterramientos femeninos dentro de las tumbas de rango superior, la existencia de bastantes tumbas ricas atribuidas a mujeres y el que algunos de los enterramientos infantiles lleven ajuar.

Evidentemente, esa explicación no es válida para el estuario del Tajo, que sigue una trayectoria similar a la del SE, hasta época campaniforme; espectaculares construcciones pétreas como las famosas de Vila Nova de Sâo Pedro o Zambujal; necrópolis asociadas; presencia de leguminosas y de tracción animal, así como posiblemente, policultivo mediterráneo; pero que no continúa esa tendencia a la ocupación permanente en la Edad del Bronce (Hopf, 1981; von der Driesch/Bössneck, 1981).

Gilman (1987), se ha planteado este problema al comparar las respectivas situaciones del Sureste de España y del Estuario del Tajo, en el III Milenio a.C. Para él, las diferencias entre una y otra radicarían menos en el tipo de economía agraria practicada que en las diferentes condiciones ambientales bajo las que ésta se desarrolló en ambas áreas. En el caso de los Millares, la aridez del medio habría implicado necesariamente la introducción de sistemas de regadío y de una inversión previa de trabajo, rentable a largo plazo. Por ello, sería susceptible a la aparición de sistemas políticos coercitivos, debido a que el campesinado difícilmente podría abandonar su inversión en tecnología agraria, a la búsqueda de una 
régimen menos opresivo. Por el contrario, en el fértil y húmedo Estuario del Tajo, las posibilidades de controlar y establecer una política de tributos sobre la producción campesina, se habrían visto limitadas ante la opción de la población de establecerse en otras zonas cultivables y donde el control político fuera menos férreo. Sin embargo y a pesar de su evidente atractivo, este modelo ofrece puntos débiles pues, por ejemplo, no explica porqué, tras la fase campaniforme, no volvemos a encontrar evidencia alguna de asentamientos estables y permanentes en esta fértil región, durante la práctica totalidad de la Edad del Bronce.

Carecemos de datos paleoambientales suficientes y fiables para especular sobre posibles fenómenos de deterioro de los suelos. Apenas, análisis polínicos como los de Alpiarça en el Ribatejo, indican que esta zona, una de las mejores áreas cerealísticas de Portugal, estuvo frecuentemente inundada y fue por lo tanto inhóspita para la ocupación humana en varias ocasiones durante la prehistoria reciente. Quizá, fenómenos de este tipo, junto con la sobreexplotación de los suelos y cambios en las tendencias económicas, con un mayor peso en el pastoreo extensivo (Harrison/Moreno, 1985), puedan ayudarnos a comprender la ausencia de asentamientos en el Estuario del Tajo y Suroeste portugués, donde previamente conocíamos una abundante ocupación entre fines del Neolítico y la época campaniforme. Asentamientos del Bronce Pleno como los de Sines en Estremadura o Faro en el Algarve, han sido interpretados como ocupaciones temporales dentro de una economía itinerante (Silva/Soares, 1981; Gamito, 1989). Datos polínicos del área de Huelva (Stevenson/Moore, 1988), parecen indicar el inicio de la explotación de la dehesa, en fechas calibradas de IVo Milenio a.C. En todo caso, el hecho cierto es que no volvemos a tener indicios de hábitat estable en la región, hasta el Bronce Final o incluso la primera Edad del Hierro.

\section{EL BRONCE FINAL Y LA TRANSICION AL HIERRO. LA TERCERA REVOLUCION AGRARIA.}

El segundo gran momento de la orfebrería peninsular es el Bronce Final y la transición a la Edad del Hierro ${ }^{4}$ y como comentaba al inicio del artículo, ello no es casualidad, porque coincide con otro momento de reorganización de la producción agraria. Sherratt (1987), comentaba acerca del III Milenio en el que se trasmiten las innovaciones de la segunda revolución agrícola, que Europa había sido abierta en el sentido literal de deforestación, y en el metafórico, de establecimiento de nuevos y más amplios contactos sociales que comunicaron todo el Continente. Algo muy similar podría decirse de la Europa del Bronce Final que es ahora un continente abierto e interconectado. Hasta tal punto, que la mayoría de los especialistas en Edad del Hierro tienen que retrotraerse a este momento para comprender la esencia de las sociedades que estudian.

Es ahora cuando se introducen o mejoran técnicas que permiten alimentar poblaciones en crecimiento y mantenerlas establemente asentadas en el suelo que cultivan. Es el caso por ejemplo, de la primera explotación masiva de la sal. Este hecho, con independencia de su aplicación al sector ganadero o a la metalurgia, hay que relacionarlo principalmente con la conservación y almacenamiento de alimentos para el invierno. Y si crece la necesidad de almacenar y conservar es porque también han aumentado las posibilidades de permanecer en el lugar. Es también el caso de la difusión hacia la Europa Central y Nórdica desde el Mediterráneo, de la Vicia faba L. (Jäger/Lozeck, 1982/173; Hopf, 1982:15; Harding, 1983:22; Idem, 1984;173; Idem, 1989:176; Marvinal, 1988:55 y 129). Esta legumi-

4. Ver nota 2 
nosa, cuya difusión va ligada a técnicas de rotación y conservación de la fertilidad del suelo, es sobre todo importante por su alto valor alimenticio, superior al del guisante y otras de su misma familia, a causa de su elevado contenido en proteínas e hidratos de carbono y porque se adapta mejor a los suelos ácidos que la mayoría de las leguminosas (Duke, 1981:275-7). Junto a ella, otra serie de plantas altamente nutritivas o resistentes a condiciones climáticas duras como el mijo, el trigo espelta, el guisante, la lenteja o ciertas plantas oleaginosas, se generalizan o ganan importancia en gran parte de Europa en este momento (Harding, 1983:22; Idem, 1989:174 y ss; Wells, 1984:47). Y por último, aunque no menos importante, es ahora cuando se produce una renovación del utillaje agrario metálico (Harding, 1976:513 y ss), y cuando en gran parte de Europa Septentrional y Noroccidental se generalizan los sistemas de parcelación de la tierra como los lynchets, field systems o celtic fields (Harding, 1976; Idem, 1989). Ello es significativo, porque parece reflejar permanencia humana sobre la tierra que se explota.

Tales cambios se tradujeron en asentamientos más estables. Wells (1983:147 y ss.), señala cómo entre 1200-800 a.C., se conocen en Centroeuropa muchos más poblados y necrópolis que en todo el Bronce Antiguo y Medio juntos y cómo estos asentamientos evidencian por vez primera, una prolongada ocupación, generación tras generación.

En el Sur de Inglaterra, los cambios en las prácticas agrícolas conducentes a la regeneración de los suelos y al asentamiento estable sobre las parcelas de cultivo, parecen iniciarse en lo que cronología británica corresponde al Bronce Medio, entre 1250-1050 a. C. en fechas no calibradas (Barrett/Bradley/ Green, 1991:222). Es el momento en el que en áreas de Wessex como Cranborne Chase, comienzan a aparecer los asentamientos cercados y los "field lynchets", que delimitan el área cultivada. Ahora, las tumbas se sitúan en los bordes de los propios campos de cultivo con las urnas directamente bajo tierra, frecuentemente sin marcadores de las mismas externamente visibles. La cerámica de estas necrópolis es la doméstica, muchas veces rota. Barrett (1989:124; Barrett/Bradley/Green, 1991:224), como también antes Bradley (1981:103; 1984:109), relacionan esta transformación del paisaje funerario, con cambios en la naturaleza de las relaciones entre los vivos y los muertos, ligados a los que se están produciendo en los sistemas de propiedad y de transmisión de la herencia, propios de la agricultura de arado y de la dote femenina. En tal sentido señala Goody (1962), que los cambios de actitud de la sociedad respecto a los antepasados, están asociados a la forma en que la propiedad se hereda. Si son los vínculos de parentesco los que determinan, de generación en generación, el papel de cada individuo dentro de su sociedad, la utilización de los funerales como ocasión de exhibición de riqueza y de competición social, de potlach, tal como Bradley (1982;1984:113 y ss; 1990: 102 y 136; 1991), y Barrett (Barrett/Needhan, 1988; Barrett, 1989 a y b; Barrett/Bradley/Green, 1991:143 y ss), los describe, carece ya de sentido. Tales cambios serían el fruto de un "revolución agraria" (Barrett/Bradley/ Green, 1991:143), a la que posiblemente no serían ajenas leguminosas como la Vicia faba L., presente ya en estas fechas en el Sur de Inglaterra (comunicación personal de Richard Bradley). Y seguramente tampoco es casual el que sea en el Bronce Medio y en la transición al Bronce Final, cuando se incrementen los intercambios con el Continente (Muckelroy, 1980 y 1981), como consecuencia en parte de las mejoras técnicas en el transporte fluvial y marítimo pero también de la mayor demanda, fruto del inicio de una época de expansión económica.

En el Mediterráneo, tras el colapso del mundo micénico, Chipre parece ocupar desde el s. XIII a.C. hasta los inicios del I. Milenio a.C., es decir, hasta la llegada de los fenicios (Ferrarese Ceruti/Vagnetti/ Lo Schiavo, 1987; Matthäu,s 1989), el vacío dejado en las rutas del Mediterráneo Central en las que la isla de Cerdeña, por su posición estratégica, ocupa un lugar destacado. Los Gale (1988:382-3), sugieren que el valor de Cerdeña tanto para minóicos y micénicos, como luego para los comerciantes 
chipriotas, derivaría no tanto de la riqueza en cobre de la isla como de su situación de intermediaria en la ruta hacia el estaño de Occidente y de la existencia en ella de hierro, del que Chipre carece. Lo cierto es que desde el s.XIII a.C., los sardos están produciendo bronces de estaño y en las mismas fechas está documentado en la isla el hierro.

Así pues, Centroeuropa y el mundo Atlántico ven llegar ahora, de modo directo o indirecto, nuevos cultígenos como el haba, nueva tecnología como el trabajo de chapa metálica y el hierro y nuevas formas de diferenciación social, ligadas como en el momento de difusión de la Revolución de los Productos Secundarios, a la exaltación de la figura del varón y del varón guerrero. Entre ellos, recipientes para comida y bebida comunitarias -y vale la pena recordar cómo recientemente Gerloff (1986), ha vuelto a insistir en el origen mediterráneo de los calderos atlánticos- nuevas formas de armamento ofensivo y defensivo; como cascos, corazas, escudos; nuevas formas de vestido y adorno, como fíbulas, broches, espejos o pinzas de depilar, así como nuevas formas de transporte y pública exhibición de poder, como el carro y el caballo, mucho antes de las colonizaciones históricas de fenicios y griegos. Junto con ellos, información, conocimiento y tecnología, susceptibles todos de ser manipulados como poderosos medios de control social e ideológico (Helms, 1988; Goody, 1987:161), van a transformar la Europa Centro-Occidental de la transición al I Milenio a.C. Todas estas innovaciones, sea cual sea su vía de llegada, son originarias del Mediterráneo. Tanto Sandars (1983:60), como Pare (1987:60) insisten en la idea de que no se trata tanto de la llegada de unos cuanto objetos importados desde el Egeo, a Centroeuropa en este caso, cuanto de la importación de tecnología y conocimiento, en definitiva del "know how", usados y adaptados a los propios contextos indígenas.

En tal marco, el papel de la Penísula Ibérica es de primera magnitud debido a su posición geoestratégica de puente entre Oriente y Occidente y entre las rutas que comunican el Atlántico y el Mediterráneo por un lado, y el Mediterráneo Occidental con Centroeuropa a través de los Pirineos, por otro.

Cada vez más indicios vienen a dar la razón a quienes, como Almagro Gorbea (1989), han defendido desde hace tiempo una precolonización de la Península Ibérica, anterior a la instalación de los fenicios en las factorías del Mediodía a partir del s.VIII a.C., frente a quienes, como la que ésto firma (Ruiz-Gálvez Priego, 1986:22-23 y 38), se habían mostrado escépticos al respecto, y que ahora se ven obligados a entonar el "Mea Culpa".

La presencia de cerámica micénica del s.XIII a.C. en el yacimiento cordobés de Montoro (Martín de la Cruz, 1988:89); de enterramientos como Roça do Casal do Meio (Spindler/Veiga Ferreira, 1973; Almagro Gorbea, 1986; Belén/Escacena, en prensa; Ruiz-Gálvez, 1991 a), que junto con las fíbulas sicilianas "ad ochio", tanto en la zona occidental como en la Oriental de la Península Ibérica (Blasco, 1987; Da Ponte, 1989; Gil-Mascarell/Peña, 1989), reflejan contactos, tal vez en ambos sentidos, entre aquella y el Mediterráneo Central en torno a los s.XI-X a.C.; la producción "in situ" en el yacimiento alicantino de Peña Negra, de metalurgia atlántica tipo "Venat", similar a la fundida en los castros portugueses de Baiôes y Coto da Pena, (González Prats, 1990; ver Da Silva, 1986: 29, nota 128 y 66 y lám XXXIII n. 9 y 10 y Da Silva, et al 1986: Est VII n 1 y 2 y comparar con Ruiz-Gálvez, 1990: figs $3 / 1$ y $3 / 2)^{5}$; y la presencia en el heterogéneo depósito de Baiôes de elementos mediterráneos como recipientes metálicos, pasarriendas o un recipiente de bronce sostenido por ruedas, de inspiración chipriotas (Silva et al., 1986: Est II, VIII y IX; Catling, 1964 fig 23 n 5 y 6, Pl 36a n y j y 48 g-i y págs 210-211 y 262; Matthäu,s 1985: Tafn, 90,91,93 n 692;100 y 100 n 704; 105; 127 b y 133 n 2 y págs 137-9; Schiavo/Macnamara/Vagnetti, 1985:48-51 y figs 14 n 4 y 5 y figs 14 n 1 a 3 y 15 n 1, 2 y 6;

5. Como hasta la fecha, las únicas evidencias de fundición "in situ" de metalurgia Vénat, se hallan en España y Portugal, cabe plantearse si es la Península Ibérica y no Francia, el foco originario de la misma. 
Ruiz-Gálvez en prensa), indican crecientes contactos atlántico-mediterráneos entre los s.X-IX a.C., fechas que coinciden con los materiales que acompañaban a un asador de procedencia atlántica en la tumba chipriota de Amathus y que Karageorghis (Karageorghis/Lo Schiavo, 1989:16), sitúa entre el Chipriogeométrico I (1050-950 a.C.) y II (950-850 a.C.), por lo que hay que aceptar estas últimas fechas para la tumba y para el asador (véase Ruiz-Gálvez en prensa a).

Y dentro de esos contactos precoloniales entre la Koiné de comerciantes del Mediterráneo CentroOriental y la Península Ibérica, se enmarca el tesoro de Villena de cerca de $10 \mathrm{kgs}$ de peso, formado por una vajilla de once cuencos de distintos tamaños y decoraciones, tres botellas de oro y dos de plata, veintiocho brazaletes cilíndricos y diversos fragmentos o piezas de revestimiento en oro, además de dos apliques de hierro y otro de ámbar, en dos de los casos, embutidos en una lámina de oro (fig. 2).

Alicia Perea (1991:100), quién ha analizado recientemente el tesoro desde un punto de vista técnico, considera Villena como un depósito de fundidor más que como un tesoro personal, porque el conjunto alberga piezas de muy diversa índole y estado de conservación. Algunas a medio hacer, otras acabadas y en buen uso y finalmente otras, rotas y en estado de desecho. Si bien ello es indudablemente cierto, también lo es que la semejanza entre sí de cuencos y botellas invitan a considerarlo como elementos de una única vajilla y seguramente también, como propiedad personal de un único individuo y de sexo masculino. Este carácter inequívocamente masculino del conjunto, lo indica su asociación a formas comunitarias de comida y bebida, algo que sobre vajillas y recipientes de muy diferentes morfologías, es propio del varón en toda la Europa del Bronce Final.

En diversas ocasiones se ha buscado un origen centroeuropeo (Almagro Gorbea, 1974 a), o una tradición mediterránea (Ruiz-Gálvez, Priego, 1989), para esta vajilla. La interpretación más coherente con su contexto y con el de la mayoría de las restantes piezas que forman el tesoro sigue siendo la de Schüle (1976), quién siempre ha tenido intuiciones geniales. Este autor considera que los cuencos son una traducción al metal de las formas y decoraciones de la cerámica de Cogotas I, presente en el único de los yacimientos de la comarca de Villena extensivamente excavado, el de Cabezo Redondo. Dos argumentos hablarían a favor de la hipótesis de Schüle:

En primer lugar, la técnica de fabricación de cuencos y botellas, a base de diferentes tipos de martillado seguidos de pulido y embutido (Perea, 1991: 103-4 y 111-114), conocida y aplicada ya con anterioridad en la Península Ibérica. En segundo lugar, porque los brazaletes rematados en puntas troncopiramidales que los acompañan, a pesar de su aparente sofisticación, están asimismo fabricados por técnicas asequibles a los orfebres peninsulares del Bronce Final, como el tallado en caliente ya sugerido por Schüle (1976:153-160; Perea, 1991:97-100). Además, corresponden a un tipo totalmente desconocido fuera de la Península Ibérica, pero que por el contrario tiene buenos antecedentes en el Levante español. Estos los proporcionan de un lado el tesoro conquense de Abía de la Obispalía (Almagro Gorbea, 1974 a), que contiene brazaletes toscamente rematados en puntas asociados a empuñaduras de espadas argáricas, lo que claramente lo sitúa en el Bronce Antiguo/Medio (RuizGálvez, Priego, 1989:50). Resalto el hecho de que Abía de la Obispalía se emplaza en las estribaciones de la serranía de Cuenca, área de trashumancia tradicional desde la Meseta Oriental hacia Levante. Y con este conjunto, habría que relacionar cronológica y geográficamente el brazalete de Sepúlveda (Segovia), hoy desaparecido (Almagro Gorbea, 1974 a). El segundo antecedente para los brazaletes de Villena, lo proporciona el propio tesorillo de Cabezo Redondo de Villena (Soler, 1965), hallado accidentalmente en la ladera Este del yacimiento. El conjunto es habitualmente datado en el Bronce Final por el sólo criterio de que existe en él un fragmento de brazalete similar a los de Villena, cuando por el contrario, éste sería precedente de aquellos, pues las restantes piezas del tesorillo son diademas planas y tútuli, similares a los aparecidos en un enterramiento infan- 
til $^{6}$ del mismo yacimiento (Soler, 1987:98 y lám 36), que claramente hay que situar en el Bronce Antiguo/Medio ${ }^{7}$.

Es indudable por el contrario, que ni el ámbar ni el hierro del tesoro, ni las técnicas de aplique a base de clavos de doble punta que estas piezas lucen (Perea, 1991:102-4), son de procedencia peninsular. El que el hierro al menos en un caso, aparezca como el ámbar embutido en oro indica su apreciación por lo que Renfrew (1986), llamaría su valor primario, esto es, su carácter exótico, de mercancía desconocida y no su carácter práctico. Por ello, en contra de Perea (1991:129), creo que hay que descartar la posibilidad de su fabricación local. El punto más próximo con producción de hierro es, como se vio (vide supra), Cerdeña donde el hierro está atestiguado por primera vez en el s. XIII a.C., en contextos de importación chipriota. Desde el s.XII a.C. la industria chipriota del hierro ha alcanzado su mayor desarrollo, no obstante carecer de mineralizaciones de ese metal en la isla (Vagnetti, 1986:360; Lo Schiavo, 1989:227 y 232; Muhly/Stech, 1990:210-211). Finalmente, el sistema de apliques a base de clavos para remate de cascos, escudos y otras piezas metálicas, se conoce en Chipre al menos desde fines del s. XIII a.C. (Catling, 1964:138).

A falta de análisis físico-químicos, es imposible conocer tampoco la procedencia del ámbar, todavía en este momento en uso en el Egeo, aunque el punto de dispersión más cercano al nuestro es de nuevo, Cerdeña donde también es importado y de tipo protovilanoviano (1200-900 a.C.), y su posible procedencia, Sicilia o el mar Tirreno (Lo Schiavo/Ridgway, 1986:396-7).

Y más complejo aún es tratar de fijar su cronología. No obstante, podríamos tentativamente situarlo entre una fecha ante quem y otra post quem. El que el hierro aparezca embutido en oro como objeto exótico y valioso, permite datar el conjunto con anterioridad a la primera explotación del hierro en la Península, esto es, antes de mediados del s. VIII a.C., momento en que existen talleres de transformación de este mineral en los asentamientos fenicios de Morro de Mezquitilla y Toscanos (Schubart, 1985; Niemeyer, 1985; Ruiz-Gálvez Priego, 1989:53). El umbral cronológico superior es más difícil de situar, si bien la estratigrafía de los yacimientos del SE que como Cabezo Redondo de Villena (Soler, 1987), presentan una ocupación argárica y tras ella otra del "Bronce Tardío" con cerámicas Cogotas I, puede servirnos de alguna ayuda. De acuerdo con Martín de la Cruz (1988:89), las cerámicas micénicas de Montoro, proporcionarían una fecha post quem de 1300 a.C., para el Bronce Tardío en el Alto Guadalquivir. Por su parte Molina (1978), proponía unas fechas del s. XIII a.C. para el Bronce Tardío del Sureste. Si las aceptamos, podríamos situar el tesoro de Villena en relación con la secuencia de

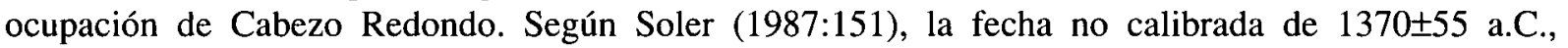
procedente de madera de una viga del Departamento XV, situaría el final del yacimiento hacia 1.200 a.C. Las cerámicas de dicho Departamento son predominantemente Bronce Antiguo/Medio o incluso más antiguas (Soler, 1987; Lám 101, n 1 a 5). Por ello, la datación radiocarbónica nos proporcionaría en todo caso un fecha post quem para las cerámicas Cogotas I del yacimiento, que representarían un momento de Bronce Tardío. De tal forma, el tesoro de Villena debería situarse entre estas fechas y el final de Cabezo Redondo, esto es, a lo largo del Bronce Tardío, entre el s.XIII/XII a.C. -margen cronológico superior- y antes de yacimientos de la zona que como Peña Negra, ya no presentan auténticas cerámicas Cogotas I y sí importaciones del Mediterráneo desde los comienzos de su ocupación (González Prats, 1990), por lo tanto, s. XI/X a.C. -margen cronológico inferior-.

6. Vuelvo a llamar la atención sobre el hecho de que la existencia de un rico ajuar en una tumba infantil, refleja una posición social heredada y claramente, no adquirida en vida.

7. El tipo de diadema plana de oro se conoce en contextos Calcolíticos/Bronce antiguo. Tútuli de oro están asimismo documentados en una tumba del Castañuelo, correspondiente al Bronce I del S.O., que claramente corresponde al Bronce Antiguo/Medio (Ruiz-Gálvez, Priego 1984:375-386. Idem 1991:285-286) 
Es posible que lo que la vajilla y las materias exóticas como el ámbar y el hierro de Villena representen sea, por una parte, un proceso de emulación tal y como lo describe Dietler (1990), quien basándose en Goody (1982), señala cómo en sociedades jerárquicas, con patrones de matrimonio endógamo y de clase, el tipo de alimentos, su preparación, servicio y consumo, sirven para diferenciar a la élite del común de la población. Y por otra, la substentación y acrecentamiento del poder, por medio de la detentación de conocimiento arcano y esotérico -en este caso el hierro- y del monopolio de los contactos con los portadores de aquel (Goody, 1987; Helms, 1988), que pudieron servir para afianzar el control social de alguien, el dueño de la vajilla y de las armas de Villena, que seguramente gozaba ya con anterioridad, de considerable poder en esta rica y estratégica región.

Es importante señalar la densa ocupación prehistórica de la comarca (fig 2), y la sorprendente concentración en su entorno de hallazgos áureos, toda vez que no existen aparentemente en ella metales, aunque recientemente Soler (1987:151), alega documentación toponímica para postular como río aurífero el Vinalopó. En su curso alto se emplaza el municipio de Villena controlando la vía hacia la costa, de la que apenas dista $60 \mathrm{kms}$ o lo que es igual, unos dos días de viaje a lomos de caballerías y menos de un día, si fuera posible la navegación fluvial (Piggott, 1983; Reid, 1986; Ruiz-Gálvez Priego, en prensa b). Controla también el cruce de una serie de caminos naturales que, de un lado, conducen desde la costa mediterránea al interior de la Meseta por el paso de Almansa y hacia La Mancha, por el "Camino viejo de Chinchilla" y de otro, hacia el valle del Guadalquivir a través del antiguo "Camino de Granada" y al Levante, por el "Camino de Játiva". Pero además, la comarca de Villena alberga una serie de importantes recursos naturales. En primer lugar un fértil valle, gracias a los recursos acuíferos de su subsuelo y a la existencia de una laguna salada, desecada en 1803, todo lo cual permitió una rica agricultura, una gran variedad y riqueza de fauna salvaje y una importante cabaña ovicaprina. En segundo lugar es el paso de las vías de trashumancia que desde la Meseta Oriental, en especial desde la Serranía de Cuenca, conducían los ganados a invernar al bajo Vinalopó. La toponimia de la zona da fe de ello, así como de la existencia de salinas, otra de las riquezas de la comarca, de las que existen testimonios de explotación desde la Antigüedad y que en la Edad Media fueron monopolio real (Matarredona, 1983:250, 272 y 349; Schüle, 1976:144; Soler, 1987: 11-12; Ruiz-Gálvez Priego, 1989:55 y nota 3 de pág 56). Una agricultura capaz de conservar la fertilidad de los suelos, junto con el control de salinas, vías de paso y de pasto, podrían explicar tal vez, el denso poblamiento de la comarca; la riqueza de hallazgos áureos en la zona; la presencia ce una vajilla de oro y plata para la comida y bebida, al estilo del monarca oriental (por ejem. Reyes, 10,21; Gilgamesh, Tab. X texto hitita y Tab X col. I texto asirio), aunque traduzca formas cerámicas locales; así como también explicaría, la forma y decoración repetitiva de los brazaletes de Abía, Sepúlveda, Cabezo Redondo y Villena, posiblemente formas de pago o tributo, al igual que lo eran las conchas o los útiles de bronce en el reino del Congo (Godsen, 1985:477), entre otros muchos ejemplos etnográficos.

Todos estos recursos naturales de la comarca pudieron aumentar de valor, con el inicio de las navegaciones prefenicias a partir del Bronce Tardío y la consiguiente demanda de carne y su conservante, pieles, productos lácteos y aún más importante, de un punto de atraque que permitiera fondear al anochecer, o hacer reparaciones (Ruiz-Gálvez Priego, 1989:55).

Esto quizá explicaría también el final de Villena, si se creara competencia por el monopolio de la intermediación comercial, para la que estarían mejor situados sitios en el curso bajo del Vinalopó. Ello justificaría asentamientos de nueva planta como Peña Negra, basado en una economía ganadera, con cerámicas pintadas pero ya no auténticas Cogotas I, e importaciones mediterráneas así como un artesano fundiendo "in situ" metalurgia atlántica, desde los propios inicios de su ocupación, (González Prats, 1983 y 1990. Véase especialmente su apéndice a la campaña de 1987; Ruiz-Gálvez Priego, 1989:55).

Es muy posible que al comercio mediterráneo prefenicio hacia la Península Ibérica, respondiera 
tempranamente una corriente en sentido inverso, desde el Occidente peninsular hacia el Mediterráneo. Ello lo justificaría no tanto la presencia de objetos peninsulares de cronología antigua en el Mediterráneo Central (Ruiz-Gálvez Priego, 1986:11), que por sí mismos no demuestran comercio indígena hacia el Mediterráneo, como la presencia de artesanos fundiendo metalurgia atlántica en el Levante, y de brazaletes similares a los de Villena en el Occidente, donde no tienen precedentes cronológicos y donde en ocasiones se fusionan, como en el caso del brazalete de Cantonha (dist. Braga), (Cardozo, 1957), con orfebrería de tipo atlántico, dando lugar a formas mixtas (véase Perea, 1991:138).

Para comprender lo que ello significa, es preciso que volvamos la mirada hacia el Occidente de la Península Ibérica, el tercer gran foco de la orfebrería del Bronce Final. Aquí poseemos por primera vez, claras evidencias de asentamientos estables y permanentes desde el s.X a.C. en fechas no calibradas, en el Centro-Norte de Portugal y en s.IX a.C. según la secuencia estratigráfica, en el Bajo Guadalquivir. Estas fechas coinciden con la reavivación de un comercio atlántico y, como vimos antes (vide supra), con navegación prefenicia en el Oeste Peninsular (Ruiz-Gálvez Priego, 1991 a).

Con independencia de los brazaletes tipo Villena ya mencionados, la más típica orfebrería de la región la constituyen los torques macizos de decoración incisa, bien estudiados por Almagro Gorbea (1974 b y 1977), quien recuerda sus precedentes y paralelos dentro de la orfebrería atlántica europea ${ }^{8}$.

Dos aspectos cabe señalar de estos torques. En primer lugar, la enorme acumulación de oro de algunos de ellos, como los portugueses de Penela, Évora y Sintra o los españoles de Sagrajas y Berzocana que pesan entre 1 y $2 \mathrm{kgs}$, por lo que podrían tener un valor emblemático de poderío y riqueza (Ruiz-Gálvez Priego, 1988 y 1989). En segundo lugar el que, como ya señalaron en su día Hawkes (1971:47) y Almagro Gorbea, (1977:61), por su pequeño diámetro, parecen pertenecer a mujeres. Este último autor (Almagro Gorbea, en prensa), indica además la coincidencia de estos torques supuestamente femeninos, con la presencia de representaciones iconográficas relativas a mujeres, en las estelas del SO, del Bronce Final. Alicia Perea (1991:101), alega sin embargo con conocimiento de causa, que aunque torques como los de Sagrajas y Berzocana presentan huellas de uso, difícilmente serían piezas de utilidad práctica, porque la exigua abertura de sus extremos no permite su encaje en el cuello. Dicha abertura, que oscila entre $10 \mathrm{~s} 6 / 6,6 \mathrm{cms}$ en los tres torques, es ciertamente excesivamente estrecha para el cuello de una mujer adulta actual, pero tal vez no para el de una mujer de la Edad del Bronce en edad de contraer matrimonio, a partir de los 12-13 años. Datos de enterramientos femeninos del Bronce Antiguo en Centroeuropa, permiten calcular una altura media de 1,55 m, (Bátora, 1991:133). Garralda (1974), propone un promedio de 1,52 m, para los enterramientos femeninos de Calcolítico/Bronce Antiguo de la Meseta. Sobre una muestra ciertamente reducida, Jacques (1890:337 y ss), calculaba una talla media para las mujeres argáricas, de 1,50 m. Finalmente, de las tres inhumaciones excavadas en el yacimiento soriano de los Tolmos de Caracena del Bronce Pleno (Jimeno, 1984), una pertenecía a una mujer en la treintena, de 1,47 m de altura (Garralda/Galera, 1984;3426). Por todo ello considero factible que esos torques fueran realmente usados por mujeres.

La localización de estos tesoros tampoco parece caprichosa pues la mayoría de ellos, como los de Sagrajas, Berzocana, Bélmez o Bodonal de la Sierra por ejemplo, controlan no tierras de potencialidad agrícola, sino vados e importantes vías de paso y su dispersión es complementaria de la de los hallazgos fluviales de espadas. Esta última circunstancia, se repite en otros lugares del Occidente

8. No se ha incluido el supuesto ajuar de una tumba de Mérida (Almagro Gorbea 1977:35-38 y fig. 9; Harrison 1977:1829), porque procede del mercado de Antigüedades por la que tanto su contexto como lugar de hallazgo son dudosos. Especialmente, en un momento como el Bronce Final, en el que la pauta es la ausencia de tumbas en Occidente. Por otra parte, su cronología es incierta y tanto Almagro Gorbea como Harrison, se han basado en la tobilleras para situar el conjunto en el Bronce Final. Nada impide sin embargo, tanto desde un punto de vista tipológico, como técnico o morfológico, una datación más antigua para el conjunto. 
atlántico y algunos tesoros, carentes aparentemente de contexto, podrían interpretarse siguiendo a Bradley (1984:110-111; Ibidem:1990:136), como posibles ajuares funerarios femeninos cuyo equivalente masculino serían las espadas depositadas en las aguas, en un momento en el que en la Koiné atlántica no existen tumbas arqueológicamente identificables (Bradley, 1982, 1984 y 1990: 90 y ss: Ruiz-Gálvez Priego, 1982 y 1991: Belén/Escacena, en prensa) (fig. 3). Bradley (1990) señala que muchos de los torques de Europa Noroccidental, aparecen rotos y deformados, lo que siguiendo a Meillassoux (1977:105), interpreta como objetos usados en las transacciones matrimoniales.

¿Cómo deberíamos entender tal hecho, en el contexto de las sociedades europeas de finales de la Edad del Bronce?.

Rowlands (1980) basándose en información lingüística y en los textos homéricos, reconstruía la sociedad europea del Bronce Final como organizada en un sistema de parentesco parecido a lo que en antropología se conoce como Crow-Omaha. Es decir, sin reglas matrimoniales fijas, salvo ciertas prohibiciones que obligan y a la vez, permiten crear alianzas cada nueva generación entre grupos exógamos. De tal manera, que el poder y la jerarquía social se alcanzaban no directamente por el control de la tierra, sino del trabajo de ésta, a través del dominio de las estrategias matrimoniales y de la política de intercambios por el que se adquirían los objetos de prestigio usados en transacciones sociales, como la compra de la novia, la política del Don, etc, gracias a las cuales era posible acceder a alianzas matrimoniales con mujeres de alto rango.

$\mathrm{Y}$ eso es lo que creo que la mayoría de tales torques representan; el establecimiento de alianzas entre regiones como el Centro-Norte de Portugal, Bajo Guadalquivir, Extremadura o el Suroeste, cuyos recursos agropecuarios y mineros están ganando importancia en el marco de unas relaciones comerciales crecientemente importantes. La presencia de brazaletes del tipo Villena a lo largo de toda la fachada Occidental (Almagro Gorbea, 1977; fig 16; Ruiz-Gálvez Priego, 1984:mapa 39; Ibidem, 1989:48; Perea, 1991:fig 5), refleja asimismo la llegada de técnicas y tal vez también de mujeres, desde el SE. de la propia Península Ibérica, como parte de unas alianzas que facilitaron posiblemente, la navegación indígena entre el Atlántico y el Mediterráneo y el intercambio de metal y otras mercancías, así como de información, tecnología y conocimiento.

\section{LA EDAD DEL HIERRO O, ¿QUE SE HIZO DEL ORO?}

Si algo caracteriza a la Europa Occidental durante gran parte de la Edad del Bronce es la gran concentración, en depósitos o aislados, pero casi siempre fuera de contexto arqueológico, de útiles, joyas y armas. Eso mismo ocurre en el Occidente de la Península Ibérica, donde a lo largo de medio milenio aproximadamente, es prácticamente todo lo que conocemos de las gentes que lo habitaron y allí vivieron, tuvieron descendencia y murieron. Sin embargo, a partir de la Edad del Hierro ocurre algo parecido a lo que Bradley señalaba para Inglaterra (vide supra),: sabemos mucho más de la parte cotidiana y prosáica de su existencia que de la ritual y funeraria, pues ni armas ni joyas vuelven a aparecer en tales contextos ${ }^{9}$.

Roger Thomas (1989:277-280), rebatía en su contribución al coloquio "The Bronze Age-Iron Age Transition in Europe", la tradicional interpretación de la superioridad del hierro sobre el bronce, como

9. Sin embargo, las ocultaciones de tesoros celtibéricos en oro y sobre todo en plata, a la llegada de los romanos, indican que el metal precioso seguía usándose como adorno, aunque no depositándose en las tumbas. En cuanto a los torques galáicos que tampoco aparecen en contextos funerarios, no son anteriores, cuando se les puede datar, a la llegada de los romanos (Peña A de la en prensa) 
causa del colapso de las redes de intercambio de metal atlánticas y del final de la Edad del Bronce. Porque, como señalaba, tal superioridad hubiera sido perceptible únicamente después de su introducción y no antes. E indicaba como causa probable de tal colapso, una densidad creciente de población que habría conducido a un punto, en el que el control de la tierra y de la producción agraria empezaría a ser mucho más importante que el de los intercambios, de las alianzas matrimoniales y del trabajo del suelo. También Boserup (1976 y 1984), ha mantenido en diversas obras la tesis de que conforme la población aumenta, crece la intensidad de utilización de la tierra, se invierte más en tecnología agraria y se reducen los períodos de descanso de la misma.

Es muy posible que esas mayores densidades de población, fueran consecuencia de la incentivación agraria que se está produciendo en toda Europa desde los inicios del Bronce Final, fruto de la expansión o de la nueva introducción de cultivos y tecnología que permiten, por primera vez en una buena parte de la misma, asentamientos estables y permanentes. Y esa explicación es en mi opinión extensible al Centro-Oeste de la Península Ibérica, donde a partir del s.X a.C. en cronología no calibrada, conocemos poblados permanentes con murallas, construcción en piedra y presencia de leguminosas como el haba (Ruiz-Gálvez Priego, 1991 a). Ello es asimismo visible en el Bajo Guadalquivir donde, en palabras de Belén/Escacena (en prensa), se produce a partir del s.IX a.C. un nuevo florecimiento poblacional. Esos cambios serán por supuesto más notorios a partir de las colonizaciones históricas, en yacimientos tartésicos o que, como en el caso de Peña Negra II (González Prats, 1983 y 1990), se encuentran sometidos a una fuerte influencia colonial. Pues aumentan espectacularmente de tamaño y en ellos, además de la introducción de nuevas plantas, animales y tecnología, también el mayor número y alzado de los bóvidos se atribuyen a influencia fenicia (Amberger, 1985).

Tales cambios paulatinos que se están produciendo en buena parte de la Península a partir del Bronce Final, indican la interconexión de ésta con el resto de Europa, en un momento en el que similares convenciones en el armamento o en formas comunitarias de comida y bebida, demuestran que es un Continente abierto y que Centroeuropa y el Mundo Atlántico están comunicados entre sí y ambos, con el Mediterráneo.

Es a través de estos renovados contactos marítimos como seguramente llegan al Occidente Peninsular innovaciones tecnológicas, entre ellas nuevos cultígenos y leguminosas de alta rentabilidad como el haba. Más dificil es determinar con seguridad su punto de origen. Cabe pensar que éste fuera el área Atlántica, con quién el Occidente Peninsular está claramente vinculado cultural, comercial e ideológicamente durante el Bronce Final (Ruiz-Gálvez Priego, 1991 a) y que como vimos, al menos en el caso de Gran Bretaña (vide supra), está experimentando cambios económicos trascendentales a partir de mediados del II milenio a.C. Otra posibilidad sería que tales innovaciones hubieran llegado a través de sus contactos con el Levante español, donde se viene practicando una agricultura compleja que permite la consolidación de la población en el suelo que cultiva, desde el III Milenio a.C. Poblados levantinos como el de Cabezo Redondo, con una agricultura basada en cereales y leguminosas como el haba (Rivera Núñez/Obón de Castro/Asensio Martínez, 1988: Tab 4 n 6), y uso de arado y seguramente abonado, como indica la presencia de bóvidos en el yacimiento, y con una importante cabaña ovicáprina, reflejan una economía agraria desarrollada (Soler, 1987). Seguramente ambas posibilidades son mutuamente complementarias, en lugar de excluyentes, en un momento en el que el mar comunica, no separa y en el que los Pirineos son vía de paso y no frontera.

Sin embargo como se dijo, armas y joyas desaparecen del Occidente Atlántico a partir de la Edad del Hierro. Tal desaparición se va produciendo paulatinamente también, en el contexto funerario del resto de la Península, a pesar de que, como Teresa Chapa (1991), señalaba, las fuentes grecorromanas coetáneas de la conquista y romanización de la Península hablan de las fuertes sumas de oro y plata 
que los conquistadores obtienen como botín, o que los vencidos deben pagar como tributo. La causa de tal desaparición se debe en mi opinión menos a las transformaciones que se están produciendo en los sistemas de propiedad y herencia, que al cambio en el significado del metal y en el de los contextos sociales en el que se emplea, como consecuencia en palabras de Bradley (1990), del hundimiento del sistema socio-político precedente. Así, la paulatina desaparición del oro de los ajuares funerarios o de los ritos de paso asociados con la muerte, se debería no tanto al hecho de que éste se herede y no se deposite en la tumba, aunque ello es muy posible (ver Ransborg, 1981:112), como al hecho que señala Chapa (1991) en época ibérica, de que predomine su valor real sobre el social, esto es, su valor de cambio sobre el de uso, (Renfrew, 1986), ya que de ahora en adelante, el poder derivará menos del control de las redes de intercambio y del acceso limitado a los objetos como el oro, usados en ciertas transacciones sociales, como las matrimoniales, que de la posesión de la tierra y el control de los medios básicos de producción. Es a su desaparición de la esfera de circulación social a lo que se refiere Bradley (1990), cuando habla del colapso del comercio atlántico del metal.

Aún en la Edad del Hierro se documenta arqueológicamente la práctica del intercambio de mujeres, pero se trata en este caso, de mujeres de alto rango, auténticas princesas, utilizadas para sellar pactos políticos porque trasmiten derechos, entre ellos, los de la sucesión al oficio (vide supra).

Así por ejemplo hay que entender el enterramiento de El Carpio de Tajo, en Toledo (Pereira/Alvaro, 1990: 217-234). Se trata de una sepultura en fosa que contiene don inhumaciones, la de un adulto joven de sexo aparentemente femenino y un recién nacido. Junto con ello, un riquísimo ajuar funerario propio de una mujer de alto rango, sorprendente además por el carácter orientalizante de su elementos, algo no inhabitual en el área tartésica, pero sí en el corazón de la Submeseta Sur. Entre los abundantes y variados objetos que componen éste, destaca una clepsidra para trasvasar líquidos que sus publicadores (Ibidem:220), interpretaron como empleada junto con algunas de las urnas, para un ritual de libación funeraria; cerámica pintada como la del SO; recipientes a torno de gran tamaño; jarritas fenicias; objetos metálicos, como un posible brasero, una fíbula de tipo Alcores o los restos de un broche de cinturón, además de anillos y otros adornos personales, portados tanto por el individuo adulto como por el bebé ${ }^{10}$, de dos cuchillitos de hierro, metal excepcional en la región en estos momentos, pero no en el SO, y de un vasito de plata, finamente labrado a partir de una única chapa de plata.

Esa sería también la explicación del tesoro de La Aliseda (Cáceres), si Almagro Gorbea (1977:204), está en lo cierto al interpretar este hallazgo casual de principios de siglo, como correspondiente al ajuar de una tumba femenina. En tal caso se repetirían las extrañas características de la tumba de El Carpio. Un rico ajuar orientalizante depositado muy lejos del área tartésica.

Aún existen otras similitudes entre El Carpio y La Aliseda. Ambos enterramientos se sitúan en puntos estratégicos de rutas que conectan el SO. y su periferia, los territorios al Sur del Tajo. En el primer caso, la tumba apareció al pie del río Gévalo, afluente del Tajo, muy cerca de la estela de las Herencias (Fernández-Miranda, 1986), y del vado de Azután, donde se localizan también hallazgos del Bronce Final de espadas en las aguas, como un ejemplar de espada en lengua de carpa de El Carpio (Jiménez, 1966) y otra pistiliforme inédita, a la altura del propio vado. Este es el arranque de una vía entre la Meseta y el Suroeste -y explica seguramente las cerámicas pintadas y el hierro de castros como Alarilla (Ruiz-Gálvez Priego, 1986:37, nota 17; Méndez/Velasco, 1988)- y de conexión con la Meseta Oriental a través del sistema Tajo-Jalón. En el caso de La Aliseda, el enterramiento se localiza en un importante nudo de caminos controlando por una parte el cruce de la Sierra de San Pedro, divisoria entre las cuencas del Tajo y del Guadiana y por otro, el camino entre Cáceres y Portugal (Ruiz-Gálvez, Priego/Galán Domingo, 1991). No cabe pues otra explicación en mi opinión que interpretar ambos

10. Véase nota n. $^{\circ} 3$ 
enterramientos como pertenecientes a princesas del SO., casadas con señores locales situados en el hinterland tartésico, como parte del establecimiento de lazos de parentesco entre jefes, que garantizan la paz y la libre circulación entre ambos territorios. A la hora de su muerte, estas mujeres se harían enterrar con el ajuar traído del hogar paterno como símbolo de su rango (Ruiz-Gálvez Priego, en prensa b; Ruiz-Gálvez,Priego/Galán Domingo, 1991).

Esta misma política, como nos relatan las Fuentes textuales (Diod, XXV, 12 y Liv., XXIV, 41), y nos recordaba recientemente Juan Pereira (1987:269) a propósito de la tumba presuntamente femenina de la Dama de Baza, es la que los Barca practicaron en la Península, pues tanto Asdrubal como Aníbal se casaron con mujeres iberas de alto rango, como forma de obtener la adhesión de las tribus a las que estas pertenecían.

En franca contradicción con cuanto hasta aquí se ha dicho, estarían las repetidas referencias acerca del trabajo agrario femenino y del matriarcado, aparentemente practicado en el Norte de la Península Ibérica (Caro Baroja, 1981:347-352; Blázquez, 1968:194-5; Bermejo Barrera, 1983:141-3). Esta interpretación se basa no única pero sí fundamentalmente en un pasaje del geógrafo Estrabón $(\mathrm{III}, 4,18)$, quién afirma refiriéndose a los Cántabros (y no a todos los pueblos del norte), que: "Los hombres dan la dote a las mujeres, las hijas son las que heredan y dan mujer a sus hermanos".

Pero, como recuerda G.Pereira (1983:200), Estrabón habla en general y como si fueran lo mismo, de todos los pueblos de la cornisa cantábrica desde los Pirineos al extremo Noroccidental. El que se asocie a los pueblos del Noroeste con una agricultura primitiva de azada y un sistema matriarcal, se debe a la interpretación de este texto estraboniano en consonancia con otra cita de este o de otros escritores como Justino, acerca del trabajo femenino del campo.

Los datos arqueológicos sin embargo, contradicen tal visión, pues desde los s. VII-VI a.C. en dataciones no calibradas, hay claras evidencias en Galicia de la tendencia al hábitat permanente. Así, la edificación en piedra o la práctica de una agricultura desarrollada que posibilita mantener la fertilidad de los suelos y que emplea plantas resistentes o altamente nutritivas, como el mijo, el guisante o el haba (Vázquez Varela, 1983:151).

Bermejo Barrera (1983:142), señalaba la contradicción entre la afirmación de Estrabón acerca del sistema matrimonial y otra suya anterior (III,3,7), según la cual los pueblos del Norte "se casan como los griegos". Goody (1990:389 y ss), afirma que en la Grecia clásica existía un sistema de matrimonio con dote, en el que la novia era dotada por su familia con motivo de su boda y que en el caso de Atenas, la mujer no heredaba posteriormente, aunque podía ser constituida en heredera si no había varones. En tal caso, la heredera se casaba con un pariente cercano.

Todo ello, como ya señalaba Bermejo (1983), no casa con la existencia de un matriarcado y de la herencia de las mujeres en detrimento de los hombres. Nuevamente, Estrabón generaliza y mete en el mismo saco a todos los pueblos de la cornisa cantábrica, cuyas instituciones y nivel de desarrollo económico, no debían ser sin embargo los mismos, ni siquiera dentro del mismo territorio político (por ejem la Galicia costera o el interior).

$\mathrm{Si}$, a partir de los inicios de la Edad del Hierro en la Galicia Costera, se percibe una progresiva tendencia al hábitat estable y permanente (Peña Santos, en prensa; Ruiz-Gálvez Priego, 1991), en lo que hoy es Asturias y Santander, no poseemos información de los hábitats hasta prácticamente la llegada de los romanos (Blas Cortina/Fernández Manzano). Ello sólo es atribuible a la práctica de una economía itinerante que no facilita la permanencia humana prolongada sobre los suelos que explota. Esto no es únicamente achacable a prácticas ganaderas, pues pueblos ganaderos de la Meseta como Vetones o Celtíberos, documentan asentamientos estables y permanentes sobre una economía mixta, con una agricultura de subsistencia con rotación de cultivos y plantas forrajeras para el ganado que posibilita el que sólo una parte de la población se desplace estacionalmente con éste (Ruiz-Gálvez, 
Priego 1991 b:75). Si a alguien se le puede atribuir un sistema agrícola muy primitivo, en el caso de que podamos dar fe a las afirmaciones de Estrabón y Justino, es más a la población de las zonas de Asturias, Santander, Norte de León (Fernández-Posse/Sánchez Palencia, 1988:203 y ss), parte del País Vasco y tal vez de zonas de la Galicia Interior, pero no a toda ella.

\section{SINTESIS}

He defendido en este trabajo: 1) la existencia de cambios en la tecnología agraria de la Península Ibérica, asociados no sólo al uso del arado y de la fuerza de tracción, sino del abonado y sobre todo, de cierto tipo de leguminosas que permitieron conservar la fertilidad del suelo, aumentar su eficacia alimenticia y con ello, la estabilidad de las poblaciones sobre las parcelas de cultivo. 2) Esos cambios se produjeron en la Península lbérica como en otras partes de Europa, en dos momentos significativos: En primer lugar, en el Calcolítico y la transición a la Edad del Bronce, ligados a la difusión de la "Revolución de los Productos Secundarios" en el Sureste de la Península Ibérica, donde a partir de ese momento tenemos indicios de hábitat permanente y de posiciones sociales heredadas y no adquiridas. En segundo lugar, durante el Bronce Final y la transición al Hierro, en el que el resto de la Península, como Europa Occidental, se incorpora a esta tendencia. 3) En ambos momentos, se percibe la emergencia de la figura del varón y del varón guerrero, asociado en mi opinión, al desarrollo de un sistema patriarcal y a la vez, el paulatino cambio de significación del metal. Este no se deprecia a partir de la Edad del Hierro, sino que cambia de significado social, pasando de la esfera del Don a la de mercancía (Apparudai, 1986; Kopytoff, 1986) y probablemente ya no juega un papel básico en la adquisición de poder, sino que su posesión es consecuencia de él. Porque a partir de ahora y hasta la Revolución Industrial, el papel de cada individuo en su sociedad, se definirá en relación con la tierra.

Tal vez la explicación de este hecho, la hallemos en el contenido de la conversación que mantienen Gerald O'Hara y su hija: Escarlata se lamenta amargamente, de que el hombre que ama va a casarse con su prima de quien no está enamorado, sólo porque siguiendo las teorías del Viejo Continente, Wilkes y Hamiltons se casan siempre entre primos. Gerald argumenta que las teorías del Viejo Continente son magníficas, pues los matrimonios entre afines escogidos por los padres, permiten a las familias mantenerse fuertes y dignas generación tras generación. Solo los yankees y los criados -añade- se casan por amor, ya que eso no es lo verdaderamente importante (El subrayado es mío).

¿Pues, qué es entonces lo verdaderamente importante?, cabe preguntarse. La respuesta la tiene Gerald O’Hara: “La tierra es la única cosa del mundo que tiene algún valor (...) porque es la única que perdura. (...) Es la única cosa que merece que trabajemos por ella, que luchemos por ella, que muramos por ella". (Mitchell 1939 (1943):52-3) ${ }^{11}$.

Madrid, verano de 1991/Enero de $1992^{12}$

11. Naturalmente, no es casualidad el que tanto los O'Hara como los Hamilton y los Wilkes sean familias católicas (véase el capítulo XL de la novela). La Reforma protestante no sólo acabó con las trabas de la Iglesia a la conservación del Patrimonio dentro del grupo familiar (Goody 1986: capítulo 7), sino que favoreció la ética de la justificación por el trabajo y el surgimiento de una nueva clase, urbana e industrial. Este es el trasfondo de la novela "Lo que el viento se llevó"; el enfrentamiento entre dos éticas y dos formas de vida: la del Norte, industrial, burgués y de moral protestante y la del Sur, latifundista, aristocrática y de cultura católica.

12. Martín Almagro, Jesús Alvarez, Ana Arnanz, Teresa Chapa, Ramón Fábregas, Eduardo Galán, Alfredo Jimeno, Carlos Junquera, Maribel Martínez Navarrete, Alicia Perea, Gonzalo Ruiz Zapatero y Juan Manuel Vicent, mejoraron este texto y aportaron valiosas sugerencias y críticas. Los errores que contenga, son de la única responsabilidad de su autora. Debo además a Ana M. Arhanz la mayor parte de la bibliografía sobre macrorrestos vegetales que he manejado. Teresa Chapa tuvo la amabilidad de darme a leer el texto de su conferencia. Los dibujos de la vajilla de Villena son de Julia Sánchez y la proyección de los vasos de Caldas de Reyes, de Eduardo Galán Domingo. 


\section{BIBLIOGRAFIA}

ALMAGRo GORBEA, M. (1974 a): "Orfebrería del Bronce Final en la Península lbérica. El tesoro de Abía de la Obispalía, la orfebrería tipo Villena y los cuencos de Axtroki”. Trabajos de Prehistoria n. 31 , págs. 39 100.

(1974 b): "Los tesoros de Sagrajas y Berzocana y los torques de oro macizo del Occidente Peninsular" Actas del III ${ }^{\text {r }}$. Congreso Nacional de Arqueología. Porto, págs 259-282

(1977): El Bronce Final y el Periodo Orientalizante en Extremadura. Madrid, Bibliotheca Praehistórica Hispana n. ${ }^{\underline{9}} \mathrm{XIV}$.

(1986): "Bronce Final y Edad del Hierro. La formación de las etnias y culturas prerromanas". En F. Jorda et al. : Prehistoria de España. Págs, 341-532, Madrid, ed. Gredos.

(1989): "Arqueología e Historia Antigua: El proceso protoorientalizante y el inicio de las contactos de Tartessos con el Levante mediterráneo". Anejos de Gerion II, págs 277-288

(en prensa): "Las estelas antropomorfas de la Península Ibérica. Tipología, dispersión, cronología y significado"

AIRA RODRIGUEZ, M‥J. \& GUITIAN OJEDA, F.

(1984): "Estudios polínicos y edafológico de los yacimientos de «O Regueiriño» y «A Fontela» (Península de Morrazo)". Pontevedra Arqueológica n. ${ }^{\circ}$ 1, págs $99-112$

AMBERGER, G. (1985): Studien über Tiernochenfunde von der Iberischen Halbinsel. Müchen

APPADUARI, A. (1986): "Introduction: commodites and the politics of value". En A. Appaduari (ed.):The social life of things. Cambridge, Cambridge Univessity Press, Págs. 3-63

AYALA, M.M. \& RIVERA, D. (1987): "Las habas como ajuar funerario en la cultura argárica". Actas del Congreso Internacional de Religiones prehistóricas. Salamanca

BARRET, J.C. (1989 a): "Food, gender and metal: questions of social reproduction". En M.L. Stig Sorensen \& R. Thomas (eds.): The Bronze/Iron age transition in Europe. British Archaeological Reppors. International Series n. ${ }^{\circ} 483$, págs $304-320$

(1989 b): "Time and tradition: the ritual of everyday life", En H-A Nordström \& A. Knape (eds.): Bronze Age Studien. Transactions of the British-Skandinavian Colloquium in Stocholm.May 10-11 1985. Stockholm Historiska Museum Studies n. 5 págs. 113-126

(1990): "The momumentality of death: the character of Early Bronze Age mortuary mouns in sothern Britain”. En R.J. Bradley (Ed.): Monuments and monumentality. World Archaeology vol. 22, n. 2, págs. $179-189$

BARRET, J.C. \& NEEDHAM, S.P. (1988): "Production, circulation and exchange: problems in the interpretation of Bronze Age bronzework". En J.C. Barrett \& I. A. Kinnes (eds.): The Archaeology of context in the Neolithic and Bronze Age: recent trends. Recent Trends Serie vol. 3, Sheffield, págs. 127-140.

BATORA, J. (1991): "The reflection of economy and social structure in the cementeries of the Chlopice-Veselé and Nitra Cultures". Slovenská Archeologica T ${ }^{\circ}$ XXXIX n.ำ 1-2, págs. $91-142$

BELEN, Mª . \& ESCACENA, J.L. (en prensa): "Las comunidades prerromanas de la Baja Andalucía", En M. Almagro Gorbea et al. (eds.): Paletnología de la Península Ibérica. Revista Complutum n.․ 2

BERMEJO BARRERA, J.C. (1983): "Etnografía castreña e historiografía clásica”. En G. Pereira Menaut (ed.): Estudos de cultura castrexa e de Historia Antiga de Galica. Universidade de Santiago de Compostela. Instituto de Estudos Galegos Padre Sarmiento do C.S.I.C, págs. 129-146.

BLAS CORTINA, M. de \& FERNANDEZ MANZANO, J. (en prensa): Asturias y Cantabria en el Ier Milenio antes de Cristo". En M. Almagro Gorbea et al. (eds.): Paletnología de la Península Ibérica. Revista Complutum n. 2

BLASCO BOSQUET, C. (1987): “Un ejemplar de fíbula de codo «ad occhio» en el Valle del Manzanares". Bolentín de la Asociación española de Amigos de la Arqueología. n. 을. págs. 191-269

BLAZQUEZ MARTINEZ, J.M (1968): "Economía de los pueblos prerromanos del área no ibérica hasta la época de Augusto".En M. Tarradell (ed.): Estudios de la Economía Antigua de la Península Ibérica. Barcelona, ed. Vicens Vives 
BOSERUP, E. (1967): Las condiciones del desarrollo en la Agricultura. Madrid, ed. Tecnos

(1984): Población y cambio tecnológico. Barcelona, Ed. Critica

BRADLEY, R.J. (1980). "Subsitence, exchange and technology: a social framework for the Bronze Age in souhern England c. 1400-700 bc". En J. Barrett \& Bradley (eds.): Settlement and society in the British Later Bronze Age. British Archaeological Repports, British Series n. ${ }^{9} 83$, págs 57-75

(1981a): "Various stules or urn". Cementeries and settlement in souhern England c. 1400-1000 b.c.". En R. Chapman/I. Kinnes/K. Randsborg (eds.): The Archaeology of Death. Cambridge, New Directions in Archaeology. Págs. 93-104.

(1981 b): "Economic growth and social change: two examples from prehistoric Europe". En A. Sheridan \& G. Bailey (eds.): Economic Archaeology. Towards an integration of ecological and social approaches. British Archaeological Repports, International Series n.․ 96, págs. 231-237

(1982): “The destruction of Wealth in later Prehistory". MAN n. 17, págs. 108-122

(1984): The social fundations of prehistoric Europe. London, Logman

(1990): The passage of arms: an archaeological analysis of prehistoric hoards and votive deposits. Cambridge, Cambridge Univ. Press.

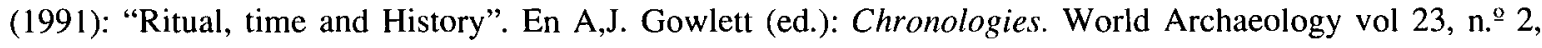
págs 209-219

BRIARD, J. (1965): Les dépots brétons et l'Age du Bronze Atlantique. Université de Rennes

(1979): "L’Age du Bronze". En P.R. Giot/J. Briard/L. Pape: Protohistoire de la Bretagne. Rennes, ed. Ouést France Université, págs. 29-213

(1984): Les tumulus de l'Armorique. París, ed. Picard

(1985): "l'Age du Bronze en Bretagne. L'homme et son evironement". En A. Boquet/M. Campy/J. Combier/

A. Thevenin/D. Vuaillat (eds.).Elements de Pré et Protohistoire Europeenne. Hommages a Jacques-Pierre Millotte. Annales littéraires de l'Université de Besançon n. ${ }^{\circ}$ 299, págs, 297-305

(1986): "Paléoenvironnement de l'homme protohistorique de l'Ouest ormoricain". III Congres national des Sociétés savantes. Poitiers, Págs, 225-234.

CANO PAN, J. \& VAZQUEZ VARELA, J.M. (1988): "Portecelo, un yacimiento de la Edad del Bronce". Trabalhos de Antropología e Etnologia.vol XXVIII fasc, 1-2. Págs 181-187

CARDOZO, M. (1957): “Da origens e tecnica do trabalho do ouro". Revista de Guimarâes LXVII, 1-2, págs. 5$46+39$ figs.

CARO BAROJA, J. (1981): Los pueblos de España. Madrid, ed., Istmo, 3ª edición, 2 Tomo

CASEY, J. et al. (1987): La familia en la España Mediterránea. (siglos XV-XIX). Barcelona, ed. Crítica

CATLING, J. (1964): Cypriot Bronzework in the Mediterranean World.Oxford, Oxford University Press

CRIADO, BOADO, F. (1988): "Mamoas y Rozas: una panorámica general sobre la distribución de los túmulos megalíticos gallegos”. Trabalhos de Antropologia e Etnologia. vol. XVIII fasc. 1-2, págs. 151-169.

CRIADO, F./AIRA RODRIGUEZ, M‥J./DIAZ FIERROS VIQUEIRA, F. (1986): La construcción del paisaje:Megalitísmo y ecología. Sierra de Barbanza. Xunta de Galicia/Consellería de Educación y Cultura. Dirección Xeral do patrimonio Artístico e Monumental.

CRIADO, F./FABREGAS, R. (1989): The megalithic phenomenon of northwest Spain: main trends". Antiquity n.․ 63, págs. $682-696$

CHAPA BRUNET, T. (1991): "El oro como elemento de prestigio social en época ibérica". Conferencia dentro del seminario: Orfebreria prerromana en la Península Ibérica. Madrid, Instituto Universitario José Ortega y Gasset, 24-26 de Junio de 1991

CHAPMAN, R. (1981 a): "Los Millares y la cronoligía relatíva de la Edad del Cobre en el SE de España". Cuadernos de Prehistoria de la Universidad de Granada. n.․․ 6, págs 75-89

(1981 b): "Archaeological theory and communal burial in prehistoric Europe". En I. Hodder/G. Isaac/N. Hammond (eds.): Pattern of the Past Studies in Honour of David Clarke. Cambridge, Cabridge University Press, Págs. 387-411

DIETLER, M. (1990): "Driven to drink: The role of dinking in the political economy and the case of Early Iron Age France”.Journal of Anthropological Archaeology n. 9, págs 352-406 
DRIECH, A. VON DER \& BOESSNECK, J. (1981): "Die Fauna von Zambujal". En E. Sangmeister \& H.Schubart: Zambujal: die Grabungen 1964 bis zum 1973. Madrider Beiträge 5 (1). págs. 303-314

DUKE, J.A. (1987): Handbook of legumes of World economic importance. New York \& London. Plune Press.

EARLE, Th. (1987): "Specialization and the production of wealth: Hawaian chiefdoms and the Inka empire. En E.M. Brumfield \& Th.K. Earle (eds.): Specialization, exchange and complex societies. Cambridge, New Directions in Archaeology. Págs 64-75

FERNANDEZ-MIRANDA FERNANDEZ, M. (1986): "La estela de las Herencias (Toledo)".Estudios en homenaje al DR. Antonio Beltrán Martínez. Págs 463-476

FERNANDEZ-POSSE, Mํ.D. \& SANCHEZ PALENCIA, F. (1988): La corona y el castro de Los Corporales $I I$. Campaña de 1983 y prospecciones en La Valderia y La Cabrera (León).Excavaciones Arqueológicas de España n.. 153.

FERRARESE CERUTI,M.L/LO SCHIAVO, F./VAGNETTI,L. (1987): "Minoici, Micenei o Ciprioti in Sardegna nella seconda metá del II Milenio a.C.". En M. Balmuth (ed.): Studies in Sardinian Archaeology III. British Archaeological Repports, International Series n.. 387 , págs. 7-34

FRANKESTEIN, S. \& ROWLANDS, M.J. (1987): "The internal structure and regional context of Early Iron Age society in South-Western Germany". Bulletin of the Institute of Archaeology. n. 15, págs. 73-112

GALE N.H. \& STOS-GALE, Z.A. (1988): "Recent evidence for a possible Bronze Age metal trade between Sardinia and the Aegean". En E.B. French \& K.A. Wardle (eds.): Problems in Greek Prehistory. Papers presented at the Centenary Conference of the British School or Archaeology at Athens. Manchester April 1986. Bristol Classical Press, págs. 349-384

GAMITO, T.J. (1989): "The wind of change blows from the east. The transition from Late Bronze Age to Iron Age in Shuthwestern Iberia and the east mediterranean". En M.L. Stig Sorensen \& R. Thomas (eds.): The Bronze Age/Iron Age transition in Europe. British Archaeological Repports. International series n. ${ }^{\circ}$ 483, págs $137-172$

GARCIA ALEN, A. (1968): “Los brazaletes de Lamela, (Silleda). El Museo de Pontevedra n.o XXII, págs.33-35 y lám. $V$

GARCIA FERNANDEZ, J. (1974): Los paisajes agrarios de la España Atlántica. Universidad de Valladolid. Departamento de Geografía.

GARRALDA, Mà.D. (1974): Estudio antropológico del Neolítico y Bronce I. Tesis Doctoral. Madrid, Universidad Complutense.

GARRALDA, Mà.D. \& GALERA, V. (1984): "Estudio antropológico". Apendice IV a A. Jimeno: Los Tolmos de Caracena (Soria). Campaña de 1977, 1978 y 1979. Nuevas bases para el estudio de la Edad del Bronce en la zona del Alto Duero. Madrid, Excavaciones Arqueológicas en España n.․ 134, págs. 341-350

GERLOFF, S. (1986): "Bronze Age Class A cauldrons. Typology, Origins and Chrology". Journal of the Royal Society of Antiquaries. Volume 116, págs, 84-115

GIL-MASCAREL, M. \& PEÑA SANCHEZ, J.L. (1989): "La fíbula «ad occhio» del yacimiento de Mola d'Agres". Saguntum n.․ 22, págs 130-145

GILMAN, A. (1987): "Unequal development in Copper Age Iberia". En E.M. Brumfiel \& T.K. Earle (eds.): Specialization, exchange and complex societies. Cambridge, New Directions in Archaeology, Págs 22-29

GODSEN CH. (1985): "Gifts and kin in Early Iron Age Europe". MAN vol, 10, n.o 3, págs. 475-493

GONZALEZ PRATS, A, (1983): Estudio arqueologico del poblamiento antiguo de la sierra de Crevillente. Anejo de la revista Lucentum n.. 1

(1990): Nueva luz sobre la Protohistoria del Sudeste. Universidad de Alicante. Caja de Ahorros Provincial de Alicante.

GOODY, J. (1962): Death, property and the ancestors. Stanford, Stanford Univ, Press

(1973): "Bridewealth and dowry in Africa and Eurasia". En J. Goody \& S.J. Tambiah: Bridewealth and Bowry. Cambridge, Cambridge Papers in Social Anthropology n.ำ 7, págs 1-58

(1976 a):Production and reproduction A comparative study of the domestic domain. Cambridge, Cambridge Papers in Social Anthropology 
(1976 b): "Inheritance, property and women: some comparative considerations". En J. Goody/J. Thirsk/E.P Thompson (eds.): Family and Inheritance. Rural Society in Western Europe, 1000-1800, Cambridge, Cambridge University Press, págs $10-36$

(1982): Cooking, Cuisine and Class. Cambridge, Cambridge University Press

(1986): La evolución de la familia y del matrimonio en Europa.Barcelona, ed., Herder

(1987): The interface between the written and the oral. Cambridge, Studies in Literacy, Family, Culture and the State.

(1990): The Oriental, the Ancient and the Primitive. Systems of marriage and the family in the pre-industrial societies of Eurasia. Cambridge, Studies in Literacy, Family, Culture and the State.

HARDING, A. (1976): "Bronze Age agricultural implements in Bronze Age Europe". En G. de G. Sieveking/I.H. Longworth/K.E. Wilson (eds.): Problems in economic and social Archaeology. London, Duckwoeth, págs 513-521.

(1983): "The Bronze Age in Central and Eastern Europe; Advances and Prospects". En F. Wendorf \& A.E. Close (eds.): Advances in world Archaeology. volume 2, págs. 1-50

(1984): "Aspects of the social evolution in the Bronze Age". En J. Bintliff (ed.): European social evolution Archaeological perspectives. Bradford, Bradford University Press. págs. 135-146.

(1989): "Interpreting the evidence por agricultural change in Late Bronze Age in Nortem Europe". En H-A. Nordström \& A. Knape (eds.): Bronze Age Studies. Transactions of the British-Scandinavian Colloquium in Stockholm. May 10-11 1985. Stockholm Historiska Museum Studies n. ${ }^{\circ}$, págs. 173-181.

HARRISON, R.J. (1977): “A Late Bronze Age grave group from Mérida (prov. Badajoz)”. Madrider Mitteilungen n. ${ }^{\circ} 17$, págs. 18-29

HARRISON, R.J. \& GILMAN, A. (1977): "Trade in the second and third Millenia B,C, between the Maghreb and Iberia". En V. Markotic (ed.): Ancient Europe and the Mediterranean Studies Presented in honour of Hugh Hecken, Warminster, Aris \& Phillips Ltd, ed., págs 90-104

HARRISON R. J. \& MORENO, G. (1985): "El policultívo ganadero o la Revolución de los Productos Secundarios". Trabajos de Prehistoria n. 92 págs 51-82.

HAWKES, Ch. (1971): “The Sintra gold collar". The British Museum Quaterly n. 35, págs 38-50

HELMS, M. (1988): Ulysses sail. An ethographic Odyssey of power, Knowledge and geographical distance. Princeton, Princeton Universtity press

HOPF, M. (1981): “Pflänzliche Reste aus Zambujal”. En E. Sangmeister \& H. Schubart: Zambujal: die Granbungen 1964 bis 1973. Madrider Beiträge n.ำ 5, págs. 315-340

(1982): Vor und de Frühgeschichtliche Kulturflazen aus dem Nördlichen Deutschland. Kataloge vor und Frühgeschichtlicher Altertümer. Band 22, Mainz,

(1987): "Les débuts de l'Agriculture et la diffucion des plantes cultives dans la Péninsule Ibérique". En J. Guilaine (dir): Premiéres communautés paysanes en Mediterrannée Occidentale. París, C.N.R.S. págs $267-$ 274

JÄGER, K-D. \& LOZEK, V. (1982): "Environmental conditions and land cultivation during the Urnfield Bronze Age in Central Europe". En A. Harding (ed.): Climatic change in Later Prehistory. Edinburgh, Edinburgh University Press. Págs. 162-178

JACQUES, V. (1890): "Etnología". En E. \& L. Siret: Las primeras edades del metal en el Sudeste de España. Barcelona, págs. 337-484 Jiménez de Gregorio, F.

(1966): "Hallazgos arqueológicos en la provincia de Toledo, Hallazgos en la vega de Santa María en el término de Mesegar". Archivo Español de Arqueologia n. ${ }^{9} 39$, págs, 174-186 y fig. 9.

JIMENO, A. (1984): Los Tolmos de Caracena (Soria). (Campaña de 1977, 1978 y 1979). Nuevas bases para el estudio de la Edad del Bronce en la zona del Alto Duero. Madrid, Excaviciones Arqueológicas de España $\mathrm{n} .^{\mathrm{o}}$ 134

JORGE, S.O. (1986): Povoados de Pré-Historia recente da regiâo de Chaves-Vila Pouca da Aguiar. Porto. Intituto de Arqueología da Facultade de Letras

(1990): “Respuesta a la recensión de M. Ruiz-Gálvez, Priego”. Trabajos de Prehistoria. n.o 47, págs. $375-378$. 
JUNQUERA, C. (1989): "El honor y el valor: Consideraciones sobre estos conceptos en la ribera del Orbigo (León)". Tierras de León n.. 74, separata sin paginación (en prensa): "Criterios antropológicos sobre el parentesco en el tránsito de la España Medieval a la Moderna". Cuadernos de Realidades Sociales.

KARAGEORGHIS, V. \& LO SCHIAVO, F. (1989): "A west mediterranean obelos from Amathus". Rivista di Studi Fenici n. ${ }^{0}$ 17, págs, 15-29

KOPYTOFF, I. (1986): "The cultural biography of things: commoditization as process". En A. Appadurai: They social lige of things. Cambridge, Cambridge Univ. Press. págs. 64-91

KRISTIANSEN, K. (1982): "The formation of tribal systems in Later european Prehistory: Northen Europe 4000-500 B.C.". En C. Renfrew/M.J. Rowlands/B.A. Seagraves (eds.): Theory and explanation in Archaelogy.London Academic Press. págs. 241-280.

LAMBERT, G./PETREQUIN, P./RICHARD, H. (1983): "Périodicité de l'habitat lacustre néolithique et rythmes agricoles". L'Anthropologie Tomo 87, n.․ 3, págs. 393-441

LEBRUN, F. \& BURGUIERE, A. (1988): "Las mil y una familias de Europa". En A. Burguiére/Ch. Klapich Zuber/M. Segalen/F. Zonabend (dir): Historia de la familia. T 2: El impacto de la modernidad. Prólogo de Jack Goody, Madrid, Alianza Editorial, págs. 19-98.

LISON TOLOSANA, C. (1987): "Estrategias matrimoniales, individualización y ethos lucenses". En J.G. Peristiany (comp): Dote y matrimonio en los paises mediterráneos. Madrid, Centro de Investigacione Sociológicas. págs. 79-105.

LOPEZ, P. (1984): "Estudio polínico de los asentamientos del yacimiento de Lavapés". Pontevedra Arqueológica. n.. 1 , págs. $179-186$

LULL, V. \& ESTEVEZ, J. (1986): "Propuestas metodológicas para el estudio de las necrópolis argáricas". En: Homenaje a Luís Siret. (1934-1984). Consejería de cultura de la Junta de Andalucia. Dirección General de Bellas Artes. págs, 441-452

MARINVAL, PH. (1988): L'Alimentación végétale en France de Mésolithique jusqu'á L'Age du Fer. Paris eds. C.N.R.S

MARTIN DE LA CRUZ, J.C. (1989): "Mykenische Keramik aus Bronzezeitlichen Siedlungen von Montoro am Guadalquivir". Madrider Mitteilungen n.. 30, págs. 77-91.

MARTINEZ-ALIER, V. (1972): "Elopement and seduction in nineteenth century Cuba". Past and Present. n." 55, págs. 91-129

MATERRADONA COLL, E. (1983): El alto Vinalopó. Estudio geográfico. Alicante, Instituo de Estudios Alicantinos.

MATTHÄUS, H. (1985): Metallgefäße und Gefäßuntersätze der Bronzezeit, der geometrischen und archaischen Periode aus Cypern. Prähistorische Bronzefunde II, n.o 8. München.

(1989): "Cypern und Sardinien im frühen 1. Jahrtausend v. Chr.". En E. Peltenburg (ed.): Early Society in Cyprus. Edinburgh, Edinburgh University Press, págs. 244-255

MEILLASSOUX, C. (1977): Mujeres, graneros y capitales. Madrid, ed. Siglo XXI s.a.

MENDEZ MADARIAGA, A. \& VELASCO STIGRAD, F. (1988): "La muela de Alarilla". Actas del ler congreso de Historia de Castilla la Mancha. TIII págs. 185-195.

MERCER, R (1981): “Introduction”. En R. Mercer (ed.): Farming Practice in British Prehistory. Edinburgh, Edinburgh University Press. págs IX-XXVI

MITCHELL, M. (1943): Lo que el viento se llevó. Barcelona, ed. Ayma Mohen, J.P., Mohen, J-P. \& Bailloud, G. (1987): La vie quotidienne. Les fouilles du Fort-Harrouard. París, ed. Picard.

MOLINA, F. (1978): "Definición y sistematización del Bronce Tardío y Final en el Sudeste de la Península Ibérica". Cuadernos de Prehistoria de la Universidad de Granada. n. ${ }^{\circ}$, págs. 159-232

MUCKELROY, K. (1980): "Two Bronze Age cargoes in british waters". Antiquity n.o 54, págs. 100-109 (1981): Middle Bronze Age trade between Britain and Europe". Proceedings of the Prehistoric Society n.․ 47, págs. 275-297

MUHLY, J. \& STECH, T. (1990): "Final observations". En F. Lo Schiavo/R. Maddin/J. Merkel/J.D. Muhly/T. Stech: Analisi metallurgiche e statistiche sui lingotti di rame della sardegna. Ministerio per i beni culturale e ambientali 
NIEMEYER, H.G. (1985): "El yacimiento fenicio de Toscanos; urbanística y función". Aula Orientalis volumen III, n. ${ }^{9} 1-2$, págs. 109-126

OLIVEIRA MARQUES, A. H. de (1968): Intoduçao à Historia da Agricultura em Portugal. Lisboa, ed. Cosmos

OTTAWAY, B. (1974): "Cluster analysis of impurity patterns in Armorico-British daggers". Archaeometry. n.. 16, págs. 221-231

PAÇO, F. do (1954): "Notas sobre sementes proto-históricas e outras, encontradas em Portugal". Actas del Congreso Nacional de Arqueología. Galicia 1953, págs. 510-515

PARE, CH. (1987): "Wheels with thickenes spokes, and the problem of cultural contacts between the Aegean world and Europe in the Late Bronze Age". Oxford Journal of Archaeology 6 (1), págs. 43-61

PEÑA SANTOS, A. de la (1984 a):“Sondeo estratigráfico en el yacimiento de «O Regueriño» (Moaña)". Pontevedra Arqueologica. n. ${ }^{\circ}$ págs. $85-90$

(1984 b): “Sondeo estratigráfico en el yacimiento de «A Fontanela» (Moaña)". Pontevedra Arqueologica. n.. 1, págs 91-98

(1984 c):"Yacimiento de Lavapés (Cangas de Morrazo), Balance de las excavaciones 1981-1982. Pontevedra Arqueológica. n. 1 , págs. 149-178

(en prensa): "El primer Milenio a.C. en el área gallega. Génesis y desarrollo del mundo castreño a la luz de la Arqueología". En M. Almagro et al. (eds.): Paletnología de la Península Ibérica. Revista Cómplutum n.o 2

PEREA, A. (1991): Orfebrería prerromana. Arqueología del Oro. Madrid, Caja de Madrid \& Comunidad de Madrid

PEREIRA MENAUT, G. (1983): "Las comunidades galáico-romanas. Habitat y sociedad en transformación". En G. Pereira Menaut (ed.): Estudos de cultura castrexa e de Historia Antigua de Galicia. Universidade e Santiago de Compostela. Instituto de Estudos Galegos Padre Sarmento do C.S.I.C. págs. 199-224

PEREIRA SIESO, J. (1987): "Necrópolis ibéricas de la Alta Andalucía”. En A. Ruiz \& A. Molinos (eds.): Iberos. Actas de las Ias Jornadas sobre el Mundo IbéricolJaen 1985. Ayuntamiento de Jaén/Junta de Andalucía , págs. 257-272.

PEREIRA, J \& ALVARO, E, de (1990): "El enterramiento de la Casa del Carpio, Belvís de la Jara (Toledo)". Actas del Ier congreso de Arqueología de la provincia de Toledo. Exma. Diputación Provincial de Toledo, págs. 215-234.

PERISTANY, J.G. (comp.) (1987): Dote y herencia en los países mediterráneos. Madrid, Centro de Investigaciones Sociológicas.

PETERS, J. \& DREICH, A. von den (1990): "Archäologische Untersuchung der Tierreste aus der Kupperzeitlichen Siedlung von Los Millares (Porv. Almería)". Studien Über frühe Tierknochenfunde von der Iberischen Halbinsel n.. 12, Müchen, págs. 51-110.

PIGGOTT, S (1983): The earliest wheeled transport from the atlantic coast to the Caspian Sea. London, Thames \& Hudson.

PONTE, S, da (1989): "As fibulas do Bronze Final Atlántico/1 Idade do Ferro do Noroeste Peninsular -Abordagem e enquadramento cultural". Trabalhos de Antropología e Etnologia. n.o 29, fasc, 1-4, págs 73-79.

RAMIL REGO, P./AIRA RODRIGUEZ, M. J./GONZALEZ MENDEZ, M/CRIADO BOADO, F. (1990): "Données paléobotaniques sur la présence de graine de brassicaceae aun N.O. de la Péninsule Ibérique". Révue de Paléoboilogie. vol, 9, n.. 2, págs. 263-272

RANSBORG, K. (1981): "Burial, succesion and early state formation in Denmark". En R. Chapman/I. Kinnes/K. Ransborg (eds.): The Archaeology of Death. Cambridge, New Directions in Archaeology, Págs. 105-121.

REDONDO, A, (ed.) (1987): Autour des parentés en Espagne aux XVIIé siécles. Histoire mythe et littérature. París, pubications de la Sorbonne

REID, P.E.W. (1986): An analysis of trade mechanisms in European Prehistory. University microfilms International. Michigan 49106.

RENFREW, C. (1986): "Varna and the emergence of wealth in prehistoric Europe". En A. Apparuddai (ed.): The social lige of things. Cambridge, Cambridge University Press, págs.141-168.

RENFREW, C. \& CHERRY, J.F. (eds.) (1984): Peer polity interaction and socio-political change. Cambridge, New Directions in Archaeology 
RENFREW, C \& SHENNAN, S. (eds.) (1984): Ranking, resource and exchange. Aspects of the Archaeology of Early European Society. Cambridge, New Directions in Archaeology.

RIVERA NUÑEZ, D \& OBON DE CASTRO, C. (1989): "La dieta cereal prehistórica y su supervivencia en el área mediterránea". Trabajos de Prehistoria. n. 46 , págs 247-254.

RIVERA NUÑEZ, D./OBON DE CASTRO, C./ASENCIO MARTINEZ, A. (1988): “Arqueobotánica y Paleoetnobotánica en el sureste de España, datos preliminares”. Trabajos de Prehistoria n. 95 , págs 317-334

ROWLANDS, M.J. (1980): "Kinship, alliance and exchange in the european Bronze Age”. En J. Barret \& R. Bradley (eds.): Settlement and Society in the British Later Bronze Age. British Archaeological Repports. British Series n. 83 , págs $15-55$

RUIZ-GALVEZ PRIEGO, E. (1990): Statut socio-juridique de la femme en Espagne au XVléme siécle. Une étude sur le mariage chrétien faite d'aprés l'épitome de matrimonio de Diego de Covarrubias y Leyva, la legislation royale et les moralistes. Paris, Didier Erudition

RUIZ-GALVEZ, PRIEGO, M. (1978): “El tesoro de Caldas de Reyes". Trabajos de Prehistoria n35, págs 173192

(1982): "Nueva espada dragada en el río Ulla: armas arrojadas a las aguas". El Museo de Pontevedra $n .{ }^{\circ}$ $X X X V I$, pags 181-196

(1984): La Península Ibérica y sus relaciones con el círculo cultural atlántico. Madrid. Universidad Complutense, 2 Tomos

(1986): "Navegación y comercio entre el Atlántico y el Mediterráneo a fines de la Edad del Bronce". Trabajos de Prehistoria n. ${ }^{-43}$, págs. 9-42

(1987): "Bronce Atlántico y «cultura» del Bronce Atlántico en la Península Ibérica". Trabajos de Prehistoria n. 44 , págs 251-264

(1988): "Oro y política. Alianzas comerciales y centros de poder en el Bronce Final del Occidente Peninsular". Espacio, Tiempo y Forma. Revista de la Facultad de Geografía e Historia. Homenaje al Profesor Eduardo Rippoll Perelló. T I Prehistoria. Uned, págs. 325-338

(1989): "La orfebrería del Bronce Final: El poder y su ostentación". Revista de Arqueologia, Extra n.o 4, págs. $46-57$

(1990): "La metalurgia de Peña Negra I". Apéndice de A. Gonzalez Prats: Nueva Luz sobre la protohistoria del Sudeste. Universidad de Alicante. Caja de ahorros Provincial, págs 317-157

(1991 a): "Songs of a wayfaring lad. Late Bronze Age Atlantic exchange and the building of the regional identity in the west Iberian Peninsula". Oxford Journal of Archaeology 10 (3), págs. 277-306

(1991 b): "La economía celtibérica". Revista de Arqueologia. Extra n.o 5, págs 72-75

(en prensa a): "The western Iberian Peninsula at the interface of the Mediterranean and the Atlantic". M. Balmuth/J. Lewthwaite/L. Prados Torreira (eds): New prespectives in western mediterranean archaeology: models from Sardinia and Iberia. Boston 4-6 Octubre 1991, Jornal of Mediterranean Studies.

(en prensa b): "Orientaciones teóricas sobre el intercambio y comercio en Prehistoria”. Galà, revista de Arqueología. n." 1 .

RUIZ-GALVEZ PRIEGO, M \& GALAN DOMINGO, E.

(en prensa): "Las estelas del Suroeste como hitos de vías ganaderas y rutas de comerio". Trabajos de Prehistoria n. 98

SANDARS, N. (1983): "North and South at the end of the Mycenean Age: aspects of an old problem". Oxford Journal of Archaeology 2 (1) págs 43-68

SANCHEZ, M. J. (1987): "O Buraco da Pala - um abrigo pré-histórico no concelho de Mirandela. (Notica preliminar das escavaçoés de 1987)”. Arqueología. n. 16, págs. 58-77.

(1989): "Datas de C14, para a pré-historia recente do Leste de Tras-os-Montes". Arqueología n.o 19, págs. $114-115$

SCHIAVO, F. lo \& RIDGWAY, D. (1986): "La Sardegna e il Mediterráneo allo scorcio del II Milenio". La Sardegna nel Mediterráneo tra el Secondo e il Primo Milenio a.C. Cagliari, págs 391-418

SCHIAVO, F. Io /MACNAMARA, E./VAGNETTI, C. (1985): "Late Cypriots imports to Italy and their influence on local bronzework". Papers of the British School at Rome. Vol, LIII págs. 1-71 
SCHUBART, H. (1985): "El asentamiento fenicio del s. VIII en el Morro de Mezquitilla, (Algarrobo, Málaga). Aula Orentalis III. n. ${ }^{\circ}$ 1-2, págs. 55-83

SCHÜLE, W. (1976): “Der bronzezeitliche Schatzfund von Villena, (Alicante)". Madrider Mitteilungen. n.. 17, págs. 142-168 + 36 Tafeln

SHENNAN, S. (1982): "Ideology, change and the European early Bronze Age". En I.Hodder (ed.): Symbolic and Structural Archaeology. Cambridge, New Directions in Archaeology. Págs. 155-161.

SHERRATT, A. (1976): "Resources, technology and trade: an essay in early European metallurgy". En G. de G. Sieveking/l. H. Longworth/K. E. Wilson (eds.): Problems in economic and social Archaeology. London, Duckworth, págs. 557-581

SILVA, A.C.F. (1986): A cultura castreja no Noroeste portugués. Paços de Ferradeira.

SILVA, A.C.F./SILVA, C.T./LOPES, A.B. (1986): "Depósito de fundidor do final da Idade do Bronze do castro da Senhora da Guia (Baiôes, S. Pedro do Sul, Viseu)". Porto. Centro de Estudos Humanísticos. págs. 73-95

SILVA, C.T. \& SOARES, J. (1981): Prehistoria del area de Sines. Sines

SOLER, J. M. (1965): El tesoro de Villena. Madrid, Excavaciones Arqueológicas en España, n. 36

(1987): Excavaciones arqueológicas en el Cabezo Redondo. Villena. Ayntamiento de Villena e Instituto de Estudios Juan Gil-Albert.

SPINDLER, K. \& VEIGA FERREIRA, O. da (1973): "Der spätbronzezeitliche Kuppelbau von der Roça de Casal do Meio in Potugal". Madrider Mitteilungen. n.. 14, págs. 60-108

STEVENSON, A.C. \& MOORE, P.D. (1988): "Studies in vegetational history of S.W. Spain II. Palynological investigations at El Acebrón , Huelva". Journal of Bigeography. n. ${ }^{\circ}$ 15, págs. 339-361

STIKA, H-P. (1988): "Botanische Untersuchungen in der bronzezeitlichen Höhensiedlung Fuente Alamo". Madrider Mitteilungen. n. .29 , págs. $64-69$

TAMBIAH, S.J. (1973): "Dowry and bridewealth, and the property rights of women in South Asia". En J. Goody \& S.J. Tambiah: Bridewealth and dowry. Cambridge, Cambridge papers in social Anthropology. n.. 7, págs. $59-169$.

THOMAS, J. (1987): "Relations of production and social change in the Neolithic or North-West Europe". MAN n.․2 22,3. págs. 405-430

THOMAS, R. (1989): "The Bronze-Iron transition in Soutern England". En M.L. Stig Sorensen \& R. Thomas (eds.): The Broze Agellron Age transition in Europe. British Archaeological Repports. International Series n.o 483, págs. 263-286

VAGNETTI, L. (1986): "L'Egeo e Cipro". En:La Sardegna nel Mediterraneo tra el Secondo e il Primo Millenio a.C. Cagliari, págs 359-367

VAGNETTI, L. \& Lo SCHIAVO, F. (1989): "Late Bronze Age long distance trade in Mediterranean: the role of the Cypriots". En E. Peltenburg (ed.): Early Society in Cyprus. Edinburgh, Edinburgh University Press, págs. $217-243$

VAZQUEZ VARELA, J.M. (1983): "Los testimonios económicos". En G. Pereira Menaut (ed.): Estudos da cultura castrexa e da Historia Antiga de Galicia. Universidade de Santiago de Compostela. Instituto de Estudos Galegos Padre Sarmiento do C.S.I.C. págs. 147-158

VAZQUEZ VARELA, J.M. \& CANO PAN, J.A. (1988): "Una nueva perspectiva de la Edad del Bronce". Trabajos de Prehistoria n.. 45, págs 281-287.

WELLS, P.S. (1983): Rural economy in the Early Iron Age. Excavations at Hascherkeller, 1978-1981. American School of Prehistoric Research, Bulletin 36

(1984): Farms, Villages and cities. Commerce and Urban origins in Late Prehistoric Europe. Ithaca and Londo. Cornell University Press

WHITTLE, A. (1985): Neolithic Europe A survey. Cambridge, Cambridge University Press.

ZOHARY, D. \& HOPF, M. (1973): "Domestication of pulses in the Old World". Science vol 182, págs. 887-894

(1989): Domestication of plants in the Old World. The origin and spread of cultivated plants in West Asia. Europe, and the Nile Valley, Oxford, Clarendon Press. 

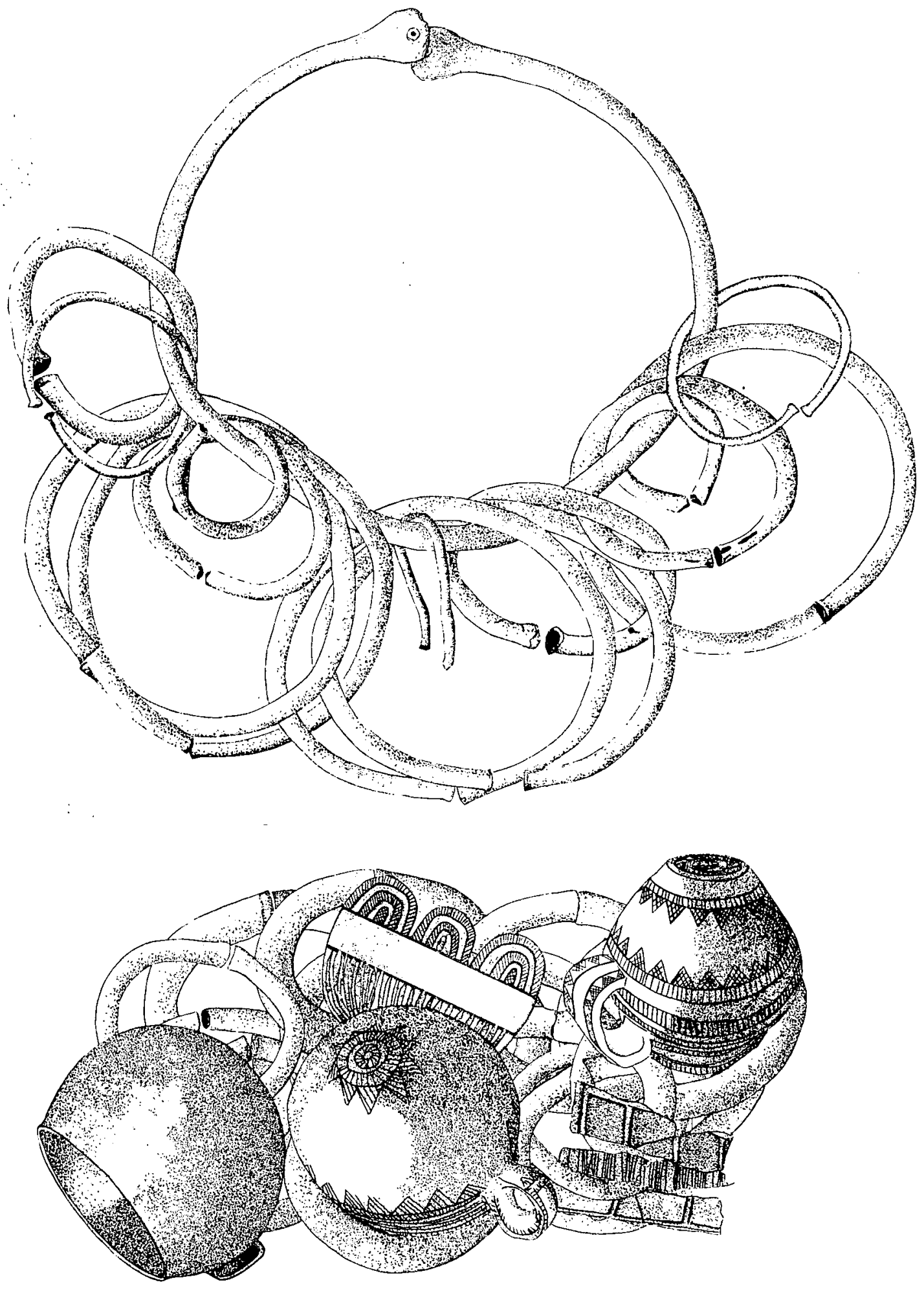

Fig. 1

ISSN: 1133-4525 ISSN-e: 2255-3924 

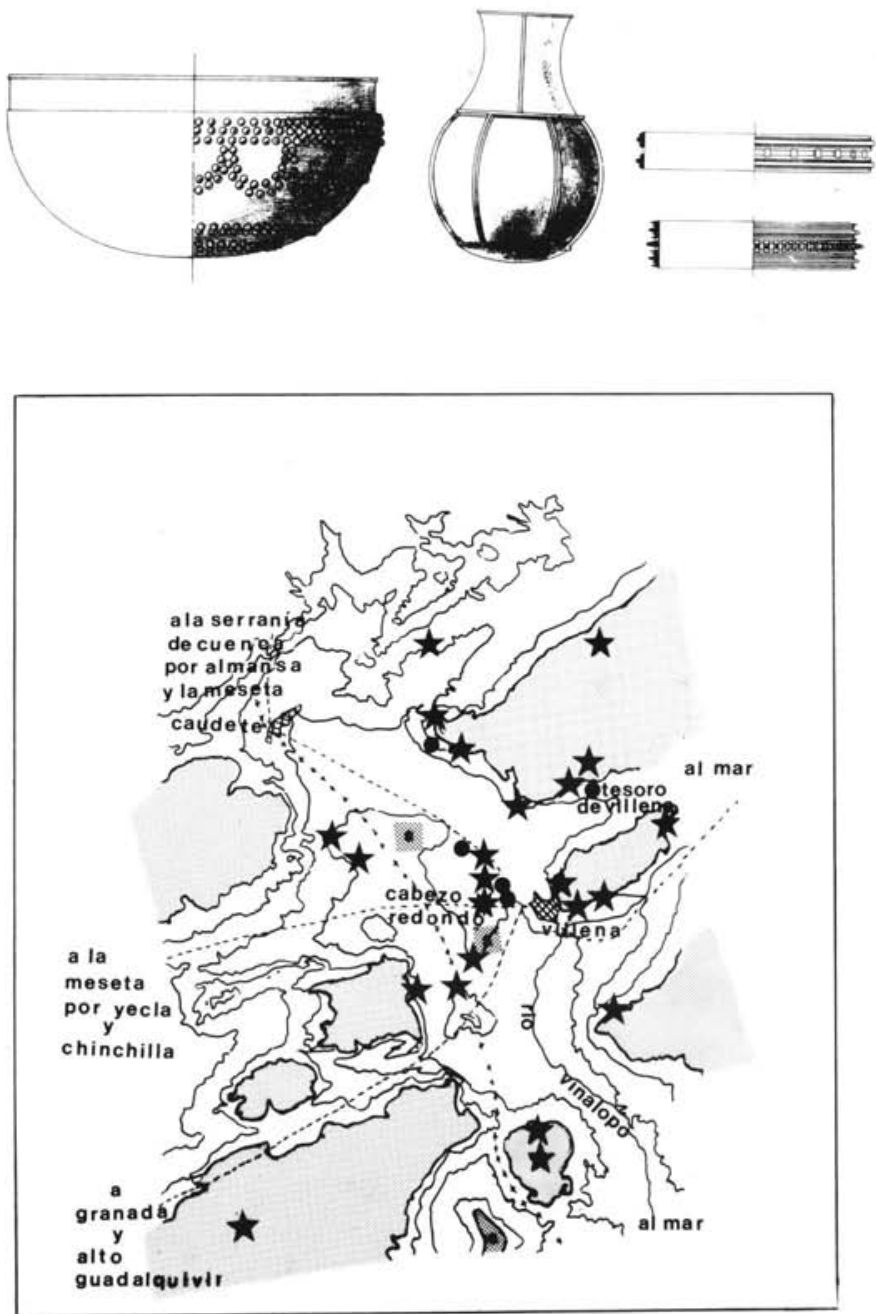

Fig. 2 

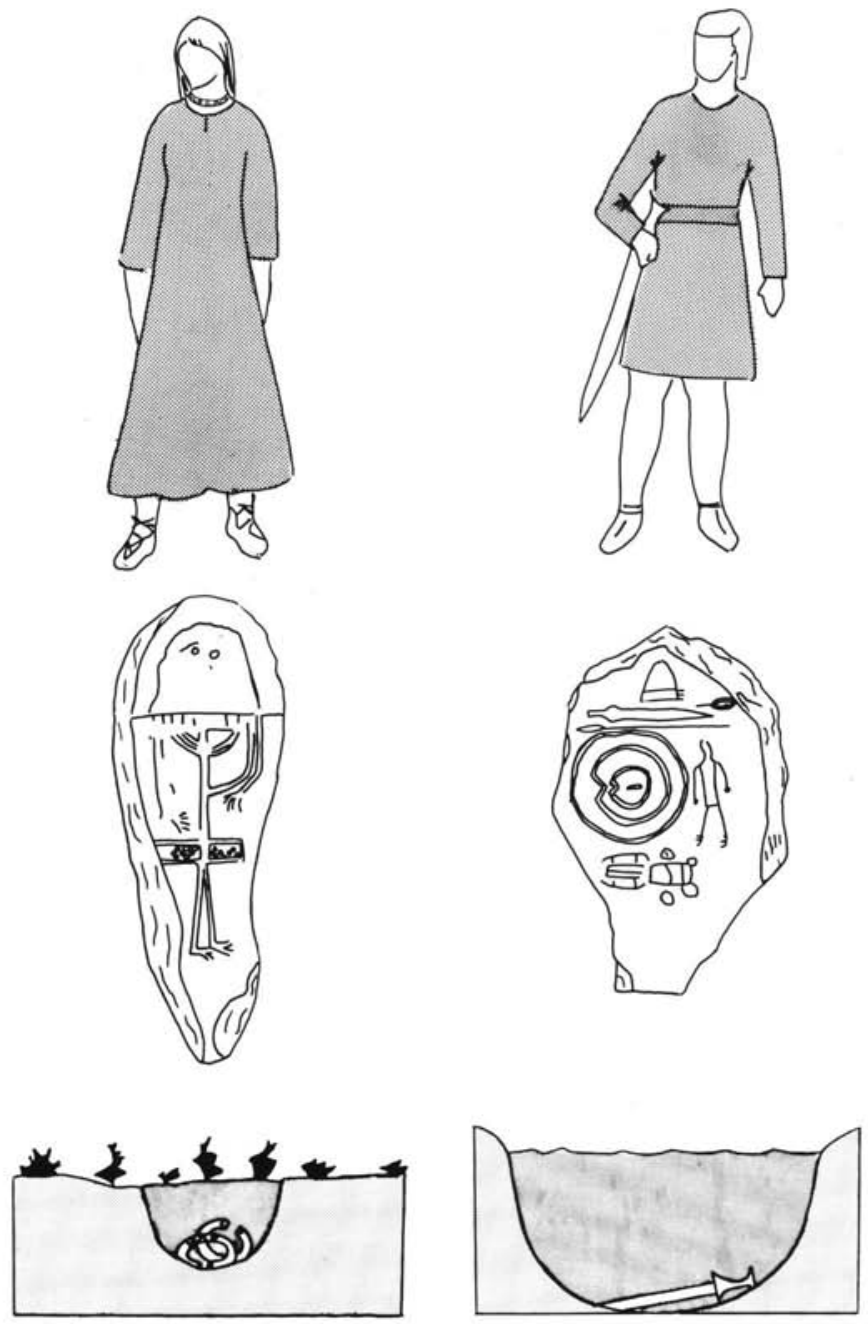

Fig. 3 